\title{
The Psychosocial Impact and Value of Participating in a Storytelling Intervention for Patients Diagnosed with Cancer: An Integrative Review
}

\author{
Andrew Soundy ${ }^{1}\left(\mathbb{B}\right.$, Kate Reid $^{2}$ \\ ${ }^{1}$ University of Birmingham, Birmingham, UK \\ ${ }^{2}$ University Hospitals Birmingham, Birmingham, UK \\ Email: A.A.Soundy@bham.ac.uk
}

How to cite this paper: Soundy, A. and Reid, K. (2019) The Psychosocial Impact and Value of Participating in a Storytelling Intervention for Patients Diagnosed with Cancer: An Integrative Review. Open Journal of Therapy and Rehabilitation, 7, 35-77.

https://doi.org/10.4236/ojtr.2019.72004

Received: March 28, 2019

Accepted: May 11, 2019

Published: May 14, 2019

Copyright $\odot 2019$ by author(s) and Scientific Research Publishing Inc. This work is licensed under the Creative Commons Attribution International License (CC BY 4.0).

http://creativecommons.org/licenses/by/4.0/

\section{(c) (i) Open Access}

\begin{abstract}
Background: Interventions have recently been developed to test the therapeutic value of storytelling for people with cancer. This evidence includes different designs, as a result an integrative review is needed that can determine the impact and value of storytelling interventions for people with cancer. Aims: To undertake an integrative review of evidence identifying the impact and outcomes from storytelling interventions for people with cancer. Methods: An integrative review of group based storytelling interventions using a qualitative led-synthesis. Results: Eleven studies were identified with a total of 493 (49 female, 16 male, 428 not disclosed) people included. Two major themes were identified: 1) content of interaction and 2) outcomes from the interventions. Six sub-themes were identified. The results provided a unique insight into the psycho-emotional impact of storytelling interventions. Conclusions: It is essential that health care professionals understand the core benefits of storytelling for people with cancer. Further interventions are needed to identify an approach which could be applied within clinical settings.
\end{abstract}

\section{Keywords}

Cancer, Storytelling, Narrative, Rehabilitation

\section{Introduction}

Storytelling is regarded as central to good clinical practice creating trust within 
the therapeutic encounter [1]. It is defined as "the effort to communicate events using words (prose or poetry), images, and sounds often including improvisation or embellishment. Stories are reflective, creative and value laden, usually revealing something important about the human condition." ([2]; page 408). In the context of chronic and palliative illnesses they are a well-established medium used e.g., [2] [3]. Storytelling interventions have gained a great deal of traction for their ability to enhance health communication and clinical practice [4]. They have been identified as encouraging positive behaviours associated with diet and physical activity [5] [6]. From the perspective of people with cancer storytelling may provide a medium through which emotions can be expressed [7]. Indeed, the process of sharing a story involves a transportation of emotions as the teller relives events [8]. It is likely that sharing stories enables a positive psycho-emotional and adaptive response to illness [9].

Past reviews have considered the benefits of storytelling-interventions for individuals with cancer at the screening point e.g., [10]. However, limited studies have been included within review evidence. For instance, there was very limited evidence of storytelling as a benefit for the side effects of cancer treatment [11] or as a behavioural treatment for paediatric patients [12]. In a broader review in chronic illness only 2 out of 10 studies considered the benefits of storytelling on individuals with cancer [13]. A more comprehensive review is justified because of the limited exploration into the value of storytelling. A review needs to be inclusive of the full-range of methodologies used to consider the experience and impact of interventions on people with cancer. Past studies have used qualitative e.g. [14] [15], mixed methods e.g. [16] and quantitative studies e.g. [17] to reveal the impact and change created by storytelling interventions. Given the above, the aim of the current research is to undertake an integrative review of evidence identifying the impact and outcomes from storytelling interventions for people with cancer.

\section{Methods}

An integrative review [18] was undertaken and reported according to three traditional steps; 1) Study eligibility and literature search process, 2) Data evaluation and 3) Data synthesis. A PRISMA checklist and flow diagram was used to aid the documentation of the search techniques and outputs [19]. For the purposes of this review we assume a subtle realist paradigmatic view-point.

\subsection{Protocol and Registration}

A protocol was registered with PROSPERO with ID: CRD42018115901.

\subsection{Eligibility Criteria}

The eligibility criteria are presented according to the PICOS (Participants, Intervention, Comparator, Outcome and Study Design) acronym:

$\mathrm{P}$ 
Any participants that have been clinically diagnosed with cancer. Any age group or gender group was allowed. The evaluation of other stakeholder's view of a storytelling intervention was included. Where other stakeholders (health care professional, family, carer) were included in studies the results section had to devote at least $50 \%$ of the results to the participant with cancer to be included. Where multiple populations were used, a separate results section for patients with cancer was required. Screening based interventions were excluded.

I

A storytelling or narrative intervention had to be reflected on or examined through any means (including face to face, internet based, tele-based). The intervention had to take place within a group setting. The purpose of the study had to include looking at the impact of storytelling on the psychosocial and emotional health or behaviour of participants. The storytelling intervention had to include contact between individuals and involve sharing stories with other patients. For the purpose of this study expressive writing was excluded. Articles that did not include a specified intervention for example a narrative analysis of experiences of services were excluded. Articles that used narrative as a small part of the intervention were excluded.

C

Any active or inactive control group could be used. No control group was acceptable.

$\mathrm{O}$

Any form of data collection could be used as long as it was able to capture experiences relating to the impact of storytelling on the individual's psychosocial or emotional well-being or behaviour.

$S$

Any study design was acceptable. All thesis and conference abstracts were excluded. Studies written in English, Spanish, French and Portuguese were included. Other languages were excluded due to the absence of translation services.

\subsection{The Search Process}

A sensitive topic based search strategy adhering to recent guidelines [20] was undertaken. The search included electronic databases (until 30 November 2018) including MEDLINE, Psychology and Behavioral Sciences Collection, CINHAL, PsychINFO, SPORT Discuss, EMBASE, PEDro, ZETOC databases. The search was supplemented by selected internet resource sites including: PubMed, Turning Research to Practice, and the first 20 pages of results from the sites Google Scholar and Science Direct. Once initial articles were obtained further searching of the 5 most common journals (identified in the database search) was conducted and citation chasing was undertaken. Key words: Cancer* AND Narrative OR Illness Narrative OR Story OR Storytelling OR Expression OR Emotions AND Intervention OR Experimental OR Qualitative OR Quantitative Or Mixed Methods. 


\subsection{Study Selection}

In the first stage of the selection process authors identified articles that potentially met the criteria for inclusion. The lead author removed duplicates and two independent reviewers considered the abstract of each article. A third independent reviewer was available to establish if an article should be included.

\subsection{Data Collection Process}

A predefined extraction form was used to identify critical study-design information and demographical details as follows. Participant demographic variables (age, gender, site of cancer, staging, geographical location and setting of the study for both the patient-group and any control-group; design and implementation intervention specifics together with details of trial [21], quality appraisal summary, analysis and key results).

\subsection{Data Evaluation}

Quality assessment of qualitative studies was undertaken using the consolidated criteria for reporting qualitative research (COREQ) [22] based ona 13-item version [23]. The studies were also assessed by a more specific checklist that identifies the characteristics of qualitative studies [24]. Both authors used the checklists to identify the utility of the studies for the synthesis process. The Cochrane risk-of-bias tool allowed the internal validity to be considered for each quantitative and mixed-methods study.

\subsection{Data Synthesis}

A qualitative-led synthesis was undertaken as recommended [18]. The synthesis used open-coding, this was followed by mind-mapping of the established themes and tubulisation of results into thematic groups. The table was reduced to focus on the most common themes and the quantitative findings were used to develop the understanding around them through a final process of integration.

\section{Results}

Nine hundred and two unique records were screened. Eleven articles were identified as meeting the eligibility criteria. Figure 1 provides a PRISMA diagram representative of the information.

\subsection{Demographics}

The total number of post-treatment participants included across studies was 493 (49 female, 16 male, 428 not disclosed). There were 168 duplicate participants [25] and 10 spouses [14] not included in this number. One study used patients who were terminally ill within a hospice setting [17]. The most prevalent types of cancer identified included; Head and Neck Cancer $(\mathrm{n}=246)$, breast cancer $(\mathrm{n}=$ 173) and not stated $(n=40)$. Other types with more than one participant included gynaecological $(\mathrm{n}=8)$, Lung $(\mathrm{n}=4)$ and Stomach $(\mathrm{n}=2)$. All studies 
apart from one [26] included adults over the age of 18 years, only one study [25] provided a mean age (55.4 \pm 11.0 years). No study provided details of the number of years of living with the illness. Settings included oncology clinics $(n=4)$, were internet based interventions $(n=3)$, tele-conferences $(n=3)$ and a medieval castle (used as a cancer centre that offers courses). Most studies were undertaken in the USA $(n=7)$, with single studies taking place in Denmark, Brazil, Japan and France. The supplementary file provides a full breakdown of demographics (see Table S1).

\subsection{Data Evaluation}

All qualitative studies met pre-defined agreed criteria. Full consideration of the quality assessment is provided in the supplementary file. The quantitative studies identified some high risks-of-bias, as; 1$)$ no protocol $(\mathrm{n}=8)$, 2) no allocation concealment $(n=7)$ or 3$)$ no randomisation procedures $(n=7)$. A total of four studies [16] [17] [26] [27] had 5 domains identified as high risk-of-bias. Breakdown of the risks of bias are listed and described in Table 1. The supplementary file provides a full breakdown of data evaluation by design type; see Table S2 and Table S3 for qualitative evaluation and Table S4 for quantitative evaluation.

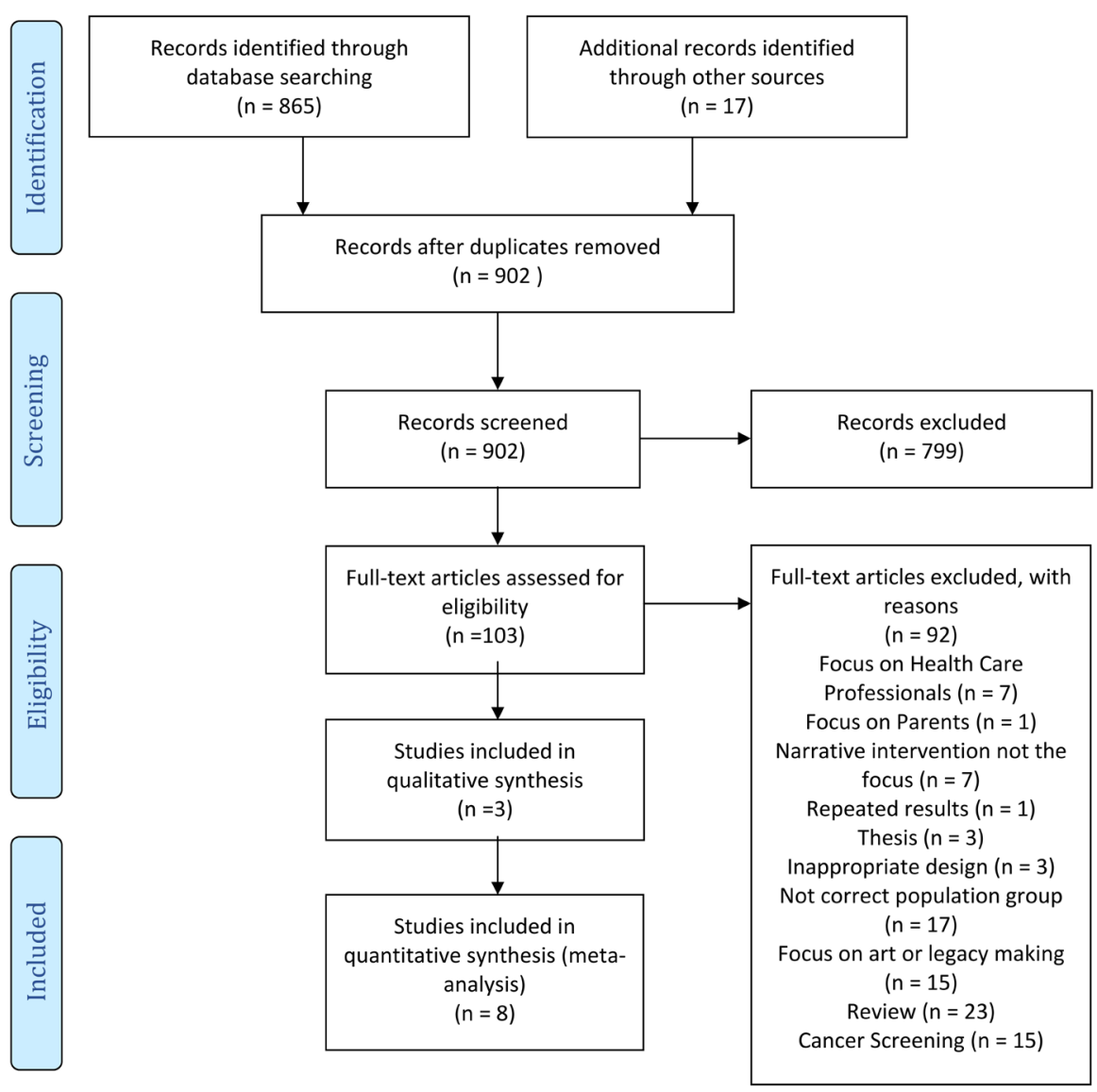

Figure 1. PRISMA 2009 flow diagram. 
Table 1. Summary assessment of the overall risk of bias.

\begin{tabular}{|c|c|c|c|c|c|c|c|c|}
\hline \multirow[t]{2}{*}{ Trial $^{*}$} & \multicolumn{6}{|c|}{$\begin{array}{l}\text { Components of risk of bias/key risk } \\
\text { criteria }\end{array}$} & \multirow[t]{2}{*}{$\begin{array}{l}\text { Summary } \\
\text { within trial }\end{array}$} & \multirow[t]{2}{*}{ Comments on high risk components-(explain briefly why) } \\
\hline & 1 & 2 & 3 & 4 & 5 & 6 & & \\
\hline $\begin{array}{l}\text { Ando et al. } \\
(2018)\end{array}$ & $\mathrm{H}$ & $\mathrm{H}$ & $\mathrm{H}$ & $\mathrm{H}$ & $\mathrm{L}$ & $\mathrm{H}$ & $\begin{array}{l}\mathrm{H}=5 \\
\mathrm{~L}=1 \\
\mathrm{U}=0\end{array}$ & $\begin{array}{l}\text { Selection bias: No identification of sequent generation or allocation } \\
\text { concealment. } \\
\text { Detection/Performance bias: No blinding of assessors mentioned. } \\
\text { Other bias: No protocol. Choice of statistics questionable. }\end{array}$ \\
\hline $\begin{array}{l}\text { Crogan et al. } \\
(2008)\end{array}$ & $\mathrm{H}$ & $\mathrm{H}$ & $\mathrm{H}$ & $\mathrm{H}$ & $\mathrm{L}$ & $\mathrm{H}$ & $\begin{array}{l}\mathrm{H}=5 \\
\mathrm{~L}=1 \\
\mathrm{U}=0\end{array}$ & $\begin{array}{l}\text { Selection bias: No identification of sequent generation or allocation } \\
\text { concealment. } \\
\text { Detection/Performance bias: No blinding of assessors mentioned. } \\
\text { Other bias: No protocol. Choice of statistics questionable. }\end{array}$ \\
\hline $\begin{array}{l}\text { Garcia-Schinzari } \\
\text { et al. (2014) }\end{array}$ & $\mathrm{H}$ & $\mathrm{H}$ & $\mathrm{H}$ & $\mathrm{H}$ & $\mathrm{L}$ & $\mathrm{H}$ & $\begin{array}{l}\mathrm{H}=5 \\
\mathrm{~L}=1 \\
\mathrm{U}=0\end{array}$ & $\begin{array}{l}\text { Selection bias: No identification of sequent generation or allocation } \\
\text { concealment. } \\
\text { Detection/Performance bias: No blinding of assessors mentioned. } \\
\text { Other bias: No protocol. Choice of statistics questionable. Sample } \\
\text { size not justified }\end{array}$ \\
\hline $\begin{array}{l}\text { Falzon et al. } \\
(2015)\end{array}$ & $\mathrm{L}$ & $\mathrm{L}$ & $\mathrm{L}$ & $\mathrm{L}$ & $\mathrm{L}$ & $\mathrm{H}$ & $\begin{array}{l}\mathrm{H}=1 \\
\mathrm{~L}=5\end{array}$ & Other bias: No protocol. \\
\hline $\begin{array}{l}\text { Heiney et al. } \\
\text { (2012) }\end{array}$ & $\mathrm{H}$ & $\mathrm{H}$ & $\mathrm{L}$ & $\mathrm{L}$ & $\mathrm{L}$ & $\mathrm{H}$ & $\begin{array}{l}\mathrm{H}=3 \\
\mathrm{~L}=3\end{array}$ & $\begin{array}{l}\text { Selection bias: No identification of sequent generation or allocation } \\
\text { concealment. } \\
\text { Other bias: No protocol. Sample size not considered. }\end{array}$ \\
\hline $\begin{array}{l}\text { Heiney et al. } \\
\text { (2013) }\end{array}$ & $\mathrm{H}$ & $\mathrm{H}$ & $\mathrm{L}$ & $\mathrm{L}$ & $\mathrm{L}$ & $\mathrm{H}$ & $\begin{array}{l}\mathrm{H}=3 \\
\mathrm{~L}=3\end{array}$ & $\begin{array}{l}\text { Selection bias: No identification of sequent generation or allocation } \\
\text { concealment. } \\
\text { Other bias: No protocol. Sample size not considered. Refers to } \\
\text { Heiney et al. (2012) for procedures and methods. }\end{array}$ \\
\hline $\begin{array}{l}\text { Heiney et al. } \\
(2015)\end{array}$ & $\mathrm{H}$ & $\mathrm{H}$ & $\mathrm{L}$ & $\mathrm{L}$ & $\mathrm{L}$ & $\mathrm{H}$ & $\begin{array}{l}\mathrm{H}=3 \\
\mathrm{~L}=3\end{array}$ & $\begin{array}{l}\text { Selection bias: No identification of sequent generation or allocation } \\
\text { concealment. } \\
\text { Other bias: No protocol. Sample size not considered. Refers to } \\
\text { Heiney et al. (2012) for procedures and methods. }\end{array}$ \\
\hline $\begin{array}{l}\text { Song et al. } \\
(2012)\end{array}$ & $\mathrm{H}$ & $\mathrm{H}$ & $\mathrm{H}$ & $\mathrm{H}$ & $\mathrm{L}$ & $\mathrm{H}$ & $\begin{array}{l}\mathrm{H}=5 \\
\mathrm{~L}=1 \\
\mathrm{U}=0\end{array}$ & $\begin{array}{l}\text { Selection bias: No identification of sequent generation or allocation } \\
\text { concealment. } \\
\text { Detection/Performance bias: No blinding of assessors mentioned. } \\
\text { Other bias: No protocol. Choice of statistics questionable. }\end{array}$ \\
\hline
\end{tabular}

${ }^{*}$ Trial denoted by first author. Risk of bias criteria: 1 , Selection bias = random sequence generation; 2, Selection bias = allocation concealment; 3 , Detection/Performance bias = blinding of personnel, assessors and participants; 4 Attrition bias = incomplete outcome data; 5 Reporting Bias = short-term selective outcome reporting; 6, Other bias = potential threats to validity e.g., consideration of a protocol. Levels of risk of bias: $\mathrm{H}$, high risk of bias; $\mathrm{U}$, unclear risk of bias; $\mathrm{L}$, low risk of bias.

\subsection{Data Synthesis}

Two major themes: content of interaction and outcomes from the interventions and six sub-themes were identified. Full details of data synthesis can be identified in the supplementary file Table S5 onwards.

\section{Major Theme 1: The Content of Interaction}

The first major theme identified had two sub-themes: 1) the expression of emotions which validated suffering and 2) the appraisal of life circumstances and experiences. 


\subsection{Subtheme a: The Expressions of Emotions Which Validated Suffering}

This sub-theme identified the importance of the opportunity to express suffering and the ability for each participant to consider and offer true and experienced feelings associated with the illness. Six [14] [15] [16] [25] [26] [28] of the eleven studies identified content within this theme.

Individuals had an opportunity to discuss fears and worries which were aspects of the situation that were exclusive to the group [15] [24] [26] [28]. The group environment represented a space where judgement from others about individual's story/ies was suspended or limited [15]. Shared topics included fear of suffering, mental exhaustion and a sense of isolation [28]. Song et al. [16] identified that around a fifth $(22.7 \%, \mathrm{n}=13 / 61)$ of the conversations were focussed on pain or suffering and similar proportion around fears and concerns related to the cancer recurring and/or symptoms worsening $(18.2 \%, n=11 / 61)$. This may vary by type of medium used within the studies. For instance, only $19.7 \%$ ( $\mathrm{n}=$ $12 / 61)$ of video postings $(n=12 / 61)$ on the internet had a direct reference to cancer.

In a study by Heiney et al. [25] over half the respondents $(64.1 \%, \mathrm{n}=25 / 39)$ identified that having others listen and feeling free to talk was the best aspect of the group-discussion. Allowing individuals to talk openly was identified as healing for the whole group [15]. There was a very high agreement $(4.0 \pm 0.2)$ with the statement (out of a possible score of 4) that "it was good to learn from other patients about their feelings" [29]. Other studies noted that group interaction didnot have to be serious all of the time. Comedy was used as a way of providing distance from situations discussed and reduced the intensity of the discussion e.g., joking about the need of "shampoo for bald-headed people" [28]. The group environment could tolerate silences because participants felt at ease during the group sessions [15].

\subsection{Sub-Theme b: The Appraisal of Life Circumstances and Experiences}

Sub-theme $\mathrm{b}$ illustrates the importance of the group being more than just focused on emotional expressions and incorporated broader aspects of living to be included within the story-telling groups. Two of the eleven studies [16] [28] identified content for this theme.

The broader conversation that occurred could include the appraisal of participants' lives beyond the symptoms of the cancer. One participant in the study by Evans et al. [15] identified her role within the family as an aspect of life that had been impacted by cancer. She stated her situation around children was affected and required her to project a sense of being in a normal parent role. The study by Song et al. [16] illustrated that these broader and overarching conversations could include non-pharmacological treatments like nutrition, exercise, alternative medicine $(15.0 \%, \mathrm{n}=9 / 61)$ as well as an individual's interests and hobbies 
$(57.4 \%, \mathrm{n}=35 / 61)$ and unique personal qualities $(47.5 \%, \mathrm{n}=29 / 61)$.

\section{Theme 2: Outcomes from groups}

The second major theme identified common outcomes evident across the different studies. There were four sub-themes: 1) psychological healing, 2) developing a shared understanding of coping, 3) social well-being and 4) legitimising or rationalising the experiences of illness.

\subsection{Sub-Theme (a) Psychological Healing}

This sub-theme identifies the impact of the group on psychological well-being as well as an understanding of why the impact may have occurred. The sub-theme was supported by seven [15] [16] [25] [26] [27] [28] [30] of the eleven studies.

Sharing stories appeared to provide a space to aid the psychological well-being of the individual. This was illustrated by significant decreases in stress $(p<0.05$, $\mathrm{F}=12.2)$, fatalism $(p=0.03)$ and fear $(p=0.02)$ over time in comparison to a control group [30]. Another study identified that nine $(45 \%, \mathrm{n}=9 / 20)$ participants changed their original pre-group emotion to a happier emotion $(p=0.01)$ [26]. Not all changes were significant however. There was no significant change in spiritual well-being or hope identified [17], or significant impact on physical self-efficacy pain [27] or depression [25] [27] reported by storytelling groups. Although of these non-significant results all studies except Heiney et al. [25] had at least five aspects which were identified as high on the risk of bias assessment.

Being able to share, be heard by someone else and tell and retell stories within the group setting was identified as a process which eased psychological suffering [15] [25] [28]. For instance, one participant identified "If a laugh is good medicine then the chat was something that can heal, maybe not our breast cancer but our souls." [28]. This was quantified by Heiney et al. [29] who identified agreement with statements ( 0 no agreement to 4 complete agreement) that individuals; 1$)$ enjoyed the sharing experience $(3.8 \pm 0.4), 2)$ felt better about themselves as they were helped by the group $(3.8 \pm 0.4), 3)$ were able to express personal feelings $(3.72 \pm 0.45)$ and concerns $(3.72 \pm 0.45)$ within the group.

\subsection{Sub-Theme (b) Developing a Shared Understanding of Coping}

This sub-theme identified that in the process of storytelling individuals were able to describe and understand how to manage their condition because the information was shared by others enabling reflection. Four [14] [15] [25] [28] of the eleven studies supported the sub-theme.

The group environment provided a space which created the capacity to understand how to cope and manage with both a diagnosis and symptoms of cancer [15] [25] [28] [29]. One study [29] quantified this by scoring agreement with the statements out of a complete agreement of 4 . It was identified that the group "helped them cope" (3.7 \pm 0.44$)$ and "supported others to examine different ways of managing problems associated with cancer" (3.56 \pm 0.55 .)

Learning to cope included the ability manage difficult aspects of the illness 
like sexually function [28]. In the study by Evans et al. [15] Individuals identified because of the storytelling intervention that they understood how they may not be able to cope now and went on to identify the repercussions in their lives.

\subsection{Sub-Theme (c) Impact on Social Well-Being}

This sub-theme identified that in the process of storytelling individuals gained new friendships that were a source of comfort and well-being. Four studies [25] [28] [29] [30] out of eleven supported this sub-theme.

The storytelling intervention counteracted feelings of isolation [25] [28]. This was identified in a quantitative study with a subsequent significant improvement in social connection [30] and by another study as agreeing with the statement (out of 4 ) that individuals "felt supported by other group members" $(3.9 \pm 0.34)$ [29]. Personal stories of those who had survived and found ways to live with cancer were perceived as encouraging [28]. In one study [25] the majority (65\%, 26/39) of individuals identified that they were more able or empowered to seek support following attendance at the group. One study identified that the internet initially made it easier to discuss and share personal feelings [28]. However, another [15] identified a participant who regretted sharing personal information in a group setting. Another study [14] identified that the process of sharing developed slowly and it was unlikely to happen in the early stages of the group.

\subsection{Sub-Theme (d) Legitimising or Rationalising the Experiences of Illness}

This sub-theme identified that individuals felt there was an important function of the group through which they could feel able to share their experiences and feel "heard" or listened to by others. Five studies [14] [15] [28] [29] [31] out of eleven supported this sub-theme.

The following aspects of the storytelling intervention enhanced the experience of being heard and valued. This included; 1) feeling accepted by others [15], 2) entering a shared social-world of another person [14] [28], and 3) the ability to use and relate to metaphors and conversations with deep personal meaning [14]. Participants felt able to join in and relate to others [15] [28]. Relatedness was enhanced by laughter and intimacy 29] or the ability of expressions to reveal vulnerability [15]. One study identified how this relied on the participants' ability to believe and trust in the message from the other members of the group. One of the studies [31] measured "source trust" (the belief and trust in the person giving the message). This quality was higher in the storytelling group compared to comparison group $(\mathrm{T}=-10.61, \mathrm{p}<0.001)$. Source trust was also associated with more positive attitudes for instance exercise beliefs and benefits. Another study by Heiney et al. [29] identified agreement with statements ( 0 no agreement to 4 complete agreement) that individuals; 1) liked "sharing with other women with breast cancer" $(3.8 \pm 0.37), 2)$ were able to "share a thought that would not be shared with most people" $(3.63 \pm 0.5)$. Both points illustrated a willingness to 
share meaningful information within the group.

\section{Discussion}

This is the first integrative review of literature to bring together the value and impact of storytelling interventions for individuals with cancer. Results identified that often the focus and content of discussion within the storytelling group contained elements of suffering, isolation, and emotions or feelings associated with the cancer. The discussion went beyond the immediate impact of cancer. The freedom to choose stories and be open with one's expressions of concerns and worries was important within the group setting. This ability to be open benefitted patients socially and was optimised through the creation of trusting relationships that developed. The ability for all individuals to contribute to the storytelling intervention if they choose to as peers within an open atmosphere may explain the value of a storytelling intervention [13]. However, it must be noted that the ability to be free to express views may vary by setting and type of interaction as well as being a reflection of how well individuals know and trust the group.

Health-policy sets patient-centred care well-being and autonomy within the survivorship stage of the disease management. There is increasing recognition of the importance of psychosocial interventions to promote behaviour change, enhance preventative care and to express and process emotion-related responses to cancer e.g. [32]. Most evidence presented within the review shows an effect of storytelling on an individual's psycho-emotional well-being through a decrease of negative emotions such as stress or fear. These changes maybe as a direct result of patients being able to share aspects of their lives and reflect upon the impact it has on them.

A person's mood and emotion may be the most variable aspect related to adjustment and being able to share an illness stories may have a substantial impact on their mood and psychological adaptation. It has been recognised that emotions can be shared through stories which has been identified to bring about physiological changes which are beneficial to the individual [1] [3]. The current results illustrated a benefit in being able to retell one's story and this is likely associated with positive changes in psychological well-being [9]. It may be that through the natural evolution of the teller's experience the story becomes adapted and modified which enables better psychological adaptation to the situation by the individual [33].

Further, it has been identified that the process of sharing information through the medium of a personal story provides a sense of empowerment and that individuals feel liberated by the act of sharing [34]. Part of the reason for such a positive effect could be the ability to share emotions which influences an individual's well-being. The current review has highlighted that past quantitative studies may not have considered outcome measures which represent the changes that might be reported by patients participating in storytelling interventions. Story- 
telling appeared to allow sharing of coping and management strategies between participants, which promotes mental well-being and potentially enhances quality of life. This has been identified in studies of other patients with long term illnesses; including other palliative illnesses [35].

\subsection{Implications}

- Listening to stories provides a way of increasing trust between the health care professional and the patient. It allows the health care professional an opportunity to understand the patient rather than to make presumptions based on clinical information in isolation.

- Storytelling has been identified as a good intervention that can strengthen communities where the intervention takes place and benefit attitudes and behaviours. The current results support this statement and identify a need for further good quality research to develop interventions that are replicable and promote this as good practice.

- The ability to use stories as a process is readily understood by patients without a requirement to develop new skills at a time when they might have a sense of being overwhelmed.

- Outcome measures that consider social support, emotions, group social-identity or empathy around interactions may capture changes occurring in the group setting.

- It may be important to assess the impact of storytelling by considering a simple assessment from practice which can aid the process

\subsection{Limitations}

- Heterogeneity of the studies. These included: the cancer type, the geographical location, culture and setting, the type of intervention and ability to identify benefits through different communication means or types of intervention and finally the use of a standardised design and choice of outcome measures all contribute to this.

- One study Garcia-Schinzari et al. [26] used children and adolescents aged from 4 - 15 years. However the contribution of this study to the synthesis was minimal except to support the evidence of positive changes in emotions as a result of a story.

- Focus on the most common findings may limit consideration to specific findings within particular interventions or setting.

- Restriction on language may focus findings towards particular cultures.

- Consideration of other stakeholders (carers, spouse, health care professionals) to the process and its impact are not given.

\section{Conclusion}

This integrative review has provided an initial indication of the value of storytelling interventions for people with cancer. Whilst there are limitations because of 
the heterogeneity of the studies, there is consistent evidence that identifies benefit from these interventions and explains a mechanism associated with the process.

\section{Conflicts of Interest}

The authors declare no conflicts of interest regarding the publication of this paper.

\section{References}

[1] Langer, N. and Ribarich, M. (2008) Using Narratives in Healthcare Communication. Educational Gerontology, 35, 55-62. https://doi.org/10.1080/03601270802388930

[2] Haigh, C. and Hardy, P. (2011) Tell Me a Story-A Conceptual Exploration of Storytelling in Healthcare Education. Nurse Education Today, 31, 408-411. https://doi.org/10.1016/j.nedt.2010.08.001

[3] Matthews, H.F., Lannin, D.R. and Mitchell, J.P. (1994) Coming to Terms with Advanced Breast Cancer: Black Women's Narratives from Eastern North Carolina. Social Science and Medicine, 38, 789-800. https://doi.org/10.1016/0277-9536(94)90151-1

[4] Lee, H., Fawcett, J. and DeMarco, R. (2015) Storytelling/Narrative Theory to Address Health Communication with Minority Populations. Applied Nursing Research, 30, 58-60. https://doi.org/10.1016/j.apnr.2015.09.004

[5] McGloin, A.F. and Eslami, S. (2015) Digital and Social Media Opportunities for Dietary Behavioural Change. Proceedings of the Nutrition Society, 74, 139-148. https://doi.org/10.1017/S0029665114001505

[6] Perrier, M.-J. and Ginis, K.A.M. (2017) Narrative Interventions for Health Screening Behaviours: A Systematic Review. Journal of Health Psychology, 22, 375-393. https://doi.org/10.1177/1359105315603463

[7] Fioretti, C., Mazzocco, K., Riva, S., Oliveri, S., Masiero, M. and Pravettoni, G. (2016) Research Studies on Patients' Illness Experience Using the Narrative Medicine Approach: A Systematic Review. BMJ Open, 6, e011220. https://doi.org/10.1136/bmjopen-2016-011220

[8] Larkey, L.K. and Hect, M.L. (2010) A Model of Effects of Narrative as Culture-Centric Health Promotion. Journal of Health Communication, 15, 114-135. https://doi.org/10.1080/10810730903528017

[9] Soundy, A. (2018) Psycho-Emotional Content of Illness Narrative Master Plots for People with Chronic Illness: Implications for Assessment. World Journal of Psychiatry, 8, 79-82. https://doi.org/10.5498/wjp.v8.i3.79

[10] Palacios, J.F., Salem, B., Hodge, F.S., Albarrán, C.R., Anaebere, A. and Hayes-Bautista, T.M. (2015) Storytelling: A Qualitative Tool to Promote Health among Vulnerable Populations. Journal of Transcultural Nursing, 26, 346-353. https://doi.org/10.1177/1043659614524253

[11] Redd, W.H. and Jacobsen, P. (2001) Behavioral Intervention in Comprehensive Cancer Care. In: Baum, A., Revenson, T.A. and Singer, J.E., Eds., Handbook of Health Psychology, Erlbaum, Mahwah, NJ, 757-776.

[12] Satapathy, S., Kaushal, T., Bakhshi, S. and Chadda, R.K. (2018) Non-Pharmacological Interventions for Paediatric Cancer Patients: A Comparative Review and Emerging 
Needs in India. Indian Paediatrics, 55, 225-232. https://doi.org/10.1007/s13312-018-1323-3

[13] Gucciardi, E., Jean-Pierre, N., Karam, G. and Sidani, S. (2016) Designing and Delivering Facilitated Storytelling Interventions for Chronic Disease Self-Management: A Scoping Review. BMC Health Services Research, 16, 249. https://doi.org/10.1186/s12913-016-1474-7

[14] La Cour, K., Ledderer, L. and Hansen, H.P. (2016) Storytelling as Part of Cancer Rehabilitation to Support Cancer Patients and Their Relatives. Journal of Psychosocial Oncology, 34, 460-476. https://doi.org/10.1080/07347332.2016.1217964

[15] Evans, B.C., Crogan, N.L. and Bendel, R. (2008) Storytelling Intervention for Patients with Cancer: Part 1-Development and Implementation. Oncology Nursing Forum, 35, 257-264. https://doi.org/10.1188/08.ONF.257-264

[16] Song, H., Nam, Y., Gould, J., Sanders, W.S., McLaughlin, M., Fulk, J., Meeske, K.A. and Ruccione, K.S. (2012) Cancer Survivor Identity Shared in a Social Media Intervention. Journal of Paediatric Oncology Nursing, 29, 80-91.

https://doi.org/10.1177/1043454212438964

[17] Ando, M., Kukihara, H., Yamamoto, M., Ninosaka, Y., Saito, N. and Okamura, K. (2018) Feasibility and Efficacy of Narrative Approach for Spiritual Well-Being of Terminally Ill Patients at Home Hospice. Annals of Nursing and Practice, 5, 1096.

[18] Whittemore, R. and Knafl, K. (2005) The Integrative Review: Updated Methodology. Journal of Advanced Nursing, 5, 546-553.

https://doi.org/10.1111/j.1365-2648.2005.03621.x

[19] Moher, D., Liberati, A., Teltzlaff, J. and Altman, D.G., PRIMSA Group (2009) Preferred Reporting Items for Systematic Reviews and Meta-Analyses: The PRISMA Statement. PLoS Medicine, 6, e1000097. https://doi.org/10.1371/journal.pmed.1000097

[20] McGowan, J., Sampson, M., Salzwedel, D.M., Cogo, E., Foerster, V. and Lefebvre, C. (2016) PRESS Peer Review Electronic Search Strategies: 2015 Guideline Statement. Journal of Clinical Epidemiology, 75, 40-46. https://doi.org/10.1016/j.jclinepi.2016.01.021

[21] Hoffmann, T.C., Glasziou, P.P., Boutron, I., Milne, R., Perera, R., Moher, D., et al. (2014) Better Reporting of Interventions: Template for Intervention Description and Replication (TIDieR) Checklist and Guide. British Medical Journal, 348, g1687. https://doi.org/10.1136/bmj.g1687

[22] Tong, A., Sainsbury, P. and Craig, J. (2007) Consolidated Criteria for Reporting Qualitative Research (COREQ): A 32-Item Checklist for Interviews and Focus Groups. International Journal for Quality in Health Care, 19, 349-357. https://doi.org/10.1093/intqhc/mzm042

[23] Soundy, A., Roskell, C., Elder, T., Collett, J. and Dawes, H. (2016) The Psychological Processes of Adaptation and Hope in Patients with Multiple Sclerosis: A Thematic Synthesis. Open Journal of Therapy and Rehabilitation, 4, 22-47. https://doi.org/10.4236/ojtr.2016.41003

[24] Kitto, S.C., Chesters, J. and Grbich, C. (2008) Quality in Qualitative Research. The Medical Journal of Australia, 188, 243-246.

[25] Heiney, S.P., Reavis, K., Tavakoli, A., Adams, S.A., Hayne, P.D. and Weinrich, S.P. (2015) The Impact of Story on Depression and Fatigue in African-American Women with Breast Cancer. The Journal of the National Black Nurses Association, 26, 1-7.

[26] Garcia-Schinzari, N.R., Pfeifer, I., Sposito, A.M.P., Santos, L.F., Nascimento, L.C. 
and Panúncio-Pinto, M.P. (2014) Caixas de histórias como estratégia auxiliar do enfrentamento da hospitalização de crianças e adolescentes com cancer. Cadernos de Terapia Ocupacional (UFSCar), 22, 569-577.

https://doi.org/10.4322/cto.2014.079

[27] Crogan, N.L., Evans, B.C. and Bendel, R. (2008) Storytelling Intervention for Patients with Cancer: Part 2-Pilot Testing. Oncology Nursing Forum, 35, 265-272. https://doi.org/10.1188/08.ONF.265-272

[28] Høybye, M.T., Johansen, C. and Tjørnhøj-Thomsen, T. (2005) Online Interaction. Effects of Storytelling in an Internet Breast Cancer Support Group. Psycho-Oncology, 14, 211-220. https://doi.org/10.1002/pon.837

[29] Heiney, S., Adams, S.A., Wells, L.M., Johnson, H. and King, J.M. (2012) Participant Evaluation of Teleconference Support for African American Women with Breast Cancer. Cancer Nursing, 35, E24-E30. https://doi.org/10.1097/NCC.0b013e31821e9947

[30] Heiney, S.P., Underwood, S.M., Tavakoli, A., Adams, S.A., Wells, L.M. and Bryant, L.H. (2012) Randomised Trial of Therapeutic Group by Teleconference. African American Women with Breast Cancer. Cancer, 118, 3822-3832. https://doi.org/10.1002/cncr.26676

[31] Falzon, C., Radel, R., Cantor, A. and d'Arripe-Longueville, F. (2015) Understanding Narrative Effects in Physical Activity Promotion: The Influence of Breast Cancer Survivor Testimony on Exercise Beliefs, Self-Efficacy and Intension in Breast Cancer Patients. Supportive Care in Cancer, 23, 761-768. https://doi.org/10.1007/s00520-014-2422-x

[32] Gudenkauf, L.M. and Ehlers, S.L. (2018) Psychosocial Interventions in Breast Cancer Survivorship Care. The Breast, 38, 1-6. https://doi.org/10.1016/j.breast.2017.11.005

[33] Soundy, A., Dawes, H., Collett, J., Coe, S. and Rosewilliam, S. (2018) Understanding the Importance of Illness Narratives in People with Multiple Sclerosis Who Participated in an Exercise Rehabilitation Trial: A Qualitative Study. Achieves of Physiotherapy and Rehabilitation, 1, 1-20.

[34] de Jager, A., Fogarty, A., Tewson, A., Lenette, C. and Boydell, K.M. (2017) Digital Storytelling in Research: A Systematic Review. The Qualitative Report, 22, 2548-2582.

[35] Soundy, A. and Condon, N. (2015) Patients Experiences of Maintaining Mental Well-Being and Hope within Motor Neuron Disease: A Thematic Synthesis. Frontiers in Psychology, 6, 606. https://doi.org/10.3389/fpsyg.2015.00606 


\section{Supplementary File}

Table S1. The demographical and design related information for included studies.

\begin{tabular}{|c|c|c|c|c|}
\hline Study & Methodology, aim Eligibility & $\begin{array}{l}\text { Participants, Sampling } \\
\text { and Setting }\end{array}$ & Key intervention details & $\begin{array}{l}\text { Data collection } \\
\text { methods, aim and } \\
\text { focus and analysis }\end{array}$ \\
\hline $\begin{array}{l}\text { La Cour } \\
\text { et al. } \\
(2016)\end{array}$ & $\begin{array}{l}\text { Paradigmatic position: } \\
\text { Interpretivist } \\
\text { Methodology. Ethnography } \\
\text { Aim: Explore the use of } \\
\text { storytelling as part of a } \\
\text { residential cancer } \\
\text { rehabilitation intervention for } \\
\text { patients and their relatives with a } \\
\text { focus on disease management } \\
\text { Eligibility Criteria: People who } \\
\text { have dad or have cancer. People } \\
\text { who were } 18 \text { years and older. } \\
\text { Groups included only } \\
\text { Gynaecological and Lung } \\
\text { cancer (because of } \\
\text { psycho/emotional impact) }\end{array}$ & $\begin{array}{l}\text { Participants: } 20 \\
\text { individuals (patient and } \\
\text { spouse) or } 10 \text { pairs } \\
\text { Cancer type: } \\
\begin{array}{l}\text { Gynaecological cancer } \\
(\mathrm{n}=8)\end{array} \\
\text { Lung Cancer }(\mathrm{n}=2) \\
\text { Sampling Technique: } \\
\text { not identified } \\
\text { Setting: medieval castle } \\
\text { Treatment details: not given } \\
\text { Country: Denmark }\end{array}$ & $\begin{array}{l}\text { Length: } 5 \text {-day residential } \\
\text { intervention. } \\
\text { Content. topics identified to } \\
\text { psychologically and emotionally support } \\
\text { people } \\
\text { Researcher/HCPs involved: counsellors } \\
\text { with difference health and social care } \\
\text { backgrounds (no additional detail) }\end{array}$ & $\begin{array}{l}\text { Outcome measure } \\
\text { development/Pilot work: } \\
\text { Interview schedule was } \\
\text { based on field notes } \\
\text { included questions like } \\
\text { what was the course like, } \\
\text { what have you incorporated } \\
\text { into your life. } \\
\text { Duration of interview. } 2 \\
\text { hours } \\
\text { Assessor: } \\
\text { Analysis: Narrative } \\
\text { emplotment (Ricoeur, } \\
\text { 1984) }\end{array}$ \\
\hline $\begin{array}{l}\text { Høybye } \\
\text { et al. } \\
(2005)\end{array}$ & $\begin{array}{l}\text { Paradigmatic position: } \\
\text { Not stated likely interpretivist } \\
\text { Methodology: } \\
\text { Ethnographic case study } \\
\text { Aim: Consider social } \\
\text { interactions and how group } \\
\text { dynamic and social mechanism } \\
\text { benefit individuals when using } \\
\text { story to consider strategies used } \\
\text { to overcome following diagnosis } \\
\text { Eligibility Criteria: Breast } \\
\text { cancer diagnosis stage (I-IV) and } \\
\text { had undergone breast surgery } \\
\text { and had or were receiving } \\
\text { chemotherapy }\end{array}$ & $\begin{array}{l}\text { Participants: } \\
15 \text { females } \\
45 \text { years } \\
28 \text { - } 55 \text { year range } \\
\text { Married }(\mathrm{n}=12) \\
\text { Children }(\mathrm{n}=13) \\
\text { Cancer type: } \\
\text { Breast cancer } \\
\text { Sampling Technique: } \\
\text { Purposive recruitment from } \\
\text { a mailing list } \\
\text { Setting: internet chat room } \\
\text { Treatment details. } \\
\text { All had or were } \\
\text { undergoing } \\
\text { chemotherapy } \\
\text { Radiation treatment } \\
\text { ( } \mathrm{n}=13 \text { ) } \\
\text { Tamoxifen or Femar } \\
\text { ( } \mathrm{n}=6 \text { ) } \\
\text { Country: USA, Faeroe } \\
\text { Islands and Greenland }\end{array}$ & $\begin{array}{l}\text { Length: } 8 \text { months } \\
\text { Content: internet based } \\
\text { discussion shared between the group } \\
\text { Assessor/Researcher/HCPs } \\
\text { involved: Researcher } \\
\text { involvement } \\
\text { Cost: No cost to participate } \\
\text { Development rationale: need to } \\
\text { understand the social value of the internet } \\
\text { and the ability to } \\
\text { empower cancer patients to consider } \\
\text { isolation to } \\
\text { Outcome measure assessment: interview } \\
\text { with most }\end{array}$ & $\begin{array}{l}\text { Methods: face to face or } \\
\text { over } \\
\text { the internet (live chat } \\
\text { room) interviews. "Most } \\
\text { interviewed" twice. } \\
\text { Field diary of interaction } \\
\text { across chat room. } \\
\text { Outcome measure } \\
\text { development/Pilot work: no } \\
\text { specific sample questions } \\
\text { rather issues were } \\
\text { addressed: personal breast } \\
\text { cancer story, use of } \\
\text { internet, involvement in the } \\
\text { mailing list, understanding } \\
\text { of list or conversations, } \\
\text { personal social relations } \\
\text { understanding of present } \\
\text { situation and hope } \\
\text { Duration of interview: not } \\
\text { given }\end{array}$ \\
\hline
\end{tabular}




\section{Continued}

\begin{tabular}{|c|c|c|c|c|}
\hline Evans & Paradigmatic position: & Participants: & Length: $12 \times 1.5$ hour sessions & Methods: unstructured \\
\hline et al. & Not clear likely interpretivist & 10 completed ( 9 female and & & interview \\
\hline \multirow[t]{15}{*}{ (2008) } & Methodology: & 1 male) pre test ( 7 & Content: Nurse led story telling & \\
\hline & Not identified & completed post test) & intervention & Outcome measure \\
\hline & Aim: identify the meaning of the & Cancer type: any type & & development/Pilot work: \\
\hline & group & & Assessor/Researcher/HCPs involved: & One question led process \\
\hline & & Sampling Technique: & Nurse facilitator of sessions. Assessor & which was what was the \\
\hline & Eligibility Criteria: 1) Any type of & fConvenience & unclear. & experience of the group like \\
\hline & cancer was included with any & & & for you. The interviewer \\
\hline & time since diagnosis, point of & Setting: Oncology clinic at & Cost. none to participant & then showed interest and \\
\hline & treatment, ethnicity or gender 2) & medical centre & & probed answers \\
\hline & individuals were under the care & & Development rationale: development of & \\
\hline & of an physician and spoke & Treatment details: story & intervention included in two phases using & Duration of interview. 30 \\
\hline & English 3) willing to share & telling intervention across & 6 outpatients with cancer & minutes \\
\hline & information with a group & 12 sessions & & \\
\hline & & & Outcome measure assessment: & Analysis: \\
\hline & & Country: USA & unstructured interview & Thematic analysis \\
\hline \multirow{29}{*}{$\begin{array}{l}\text { Song } \\
\text { et al. } \\
(2012)\end{array}$} & Paradigmatic position: & Participants: & Length: 6 Months & Methods. Video recordings \\
\hline & Post-positivism & 14 participants between & & of stories and specific \\
\hline & & $18-29$ & Content. Single face to face orientation & assessment of outcome \\
\hline & Methodology: & No age & session. & measures \\
\hline & Mixed methods (no type given) & & & \\
\hline & & Cancer type: & Across the time period individuals recoded & Outcome measure \\
\hline & Aim: Consider the cancer & No details & their own video narratives and posted & development/Pilot work: \\
\hline & survivor identity, what was & & them & Not applicable. \\
\hline & internalised about the identity & Sampling Technique: & to the site. & \\
\hline & and consider what is shared & Purposive from a & & Duration of interview. 61 \\
\hline & during story telling and & telephone and mailing list & Assessor/Researcher/HCPs involved: A & video clips at an average \\
\hline & association to psychological & & registered nurse and member of research & length of 211 words. \\
\hline & health & Setting: Face to face & team screened for eligibility. & \\
\hline & & assessment & & Analysis: Video clips used \\
\hline & Eligibility Criteria: 1) & & Cost. None. Free smart phone provided. & a-priori analysis looking at \\
\hline & Diagnosis of cancer during & Treatment details: & & references to cancer, \\
\hline & childhood or adolescent and & smart phone provided to & Development rationale: & stereotypes and social \\
\hline & at the time of the study be aged & participants. Website created & & identity and acceptance of \\
\hline & between 18 - 29 2) off cancer & for video sharing and social & Outcome measure assessment. video & saviour identity. \\
\hline & treatment for 2 years and & networking on mobile-web & narratives and psychosocial outcome & \\
\hline & cancer free for 5 years 3 ) & application. & measures including: "Who AM I"? Test & \\
\hline & individuals with cognitive & & (Kuhn and McPartland's, 1954) & \\
\hline & impairment as a symptom of & Country: USA & Depression using Centre for & \\
\hline & their cancer were excluded & & Epidemiologic Studies-Depression Scale & \\
\hline & & & (CES-D; Radoff, 1977) & \\
\hline & & & Survivorship Self-efficacy & \\
\hline & & & (adaptation of Jerusalem and Schwarzer & \\
\hline & & & 1992) (no psychometric considerations for & \\
\hline & & & adapted test) & \\
\hline
\end{tabular}




\section{Continued}

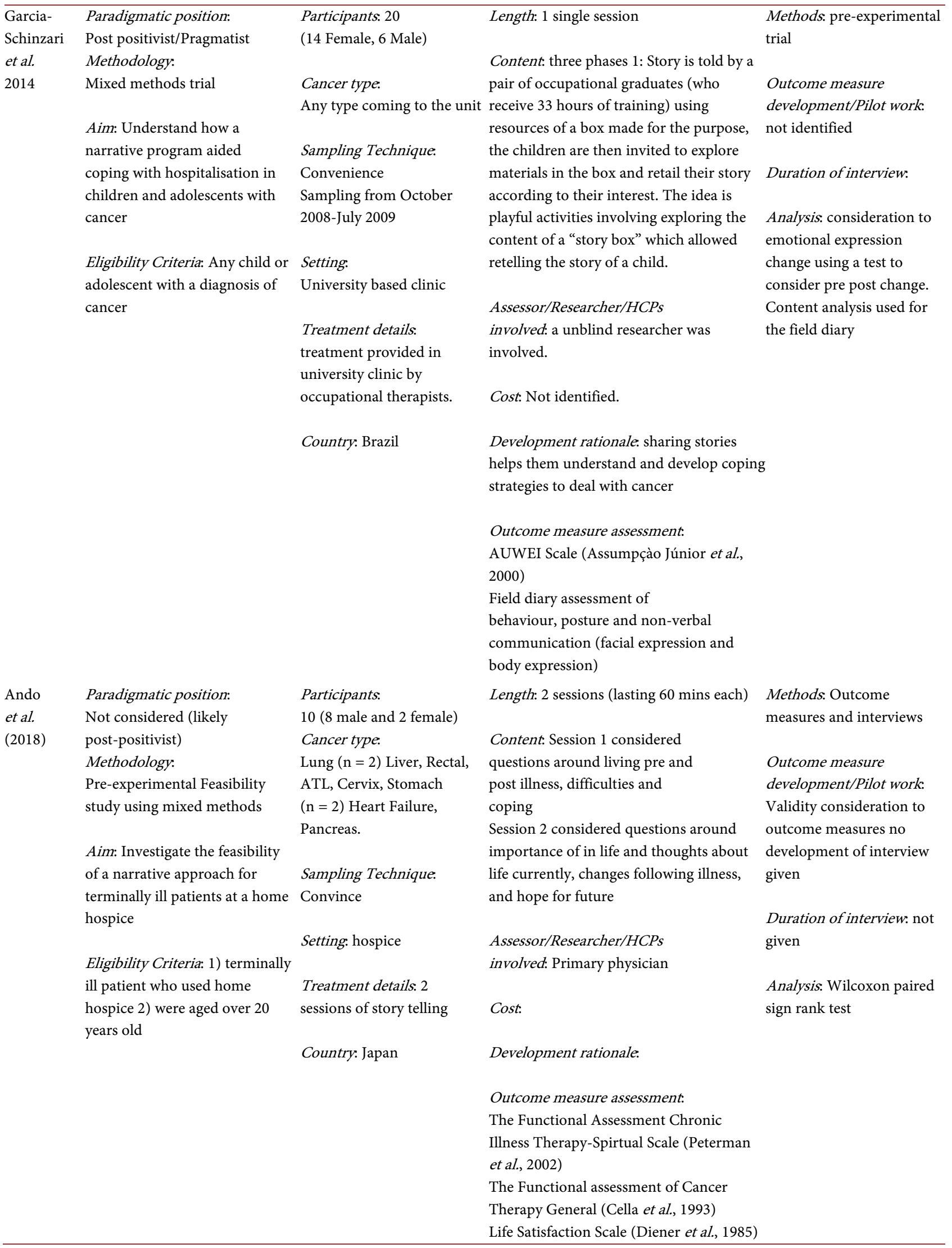




\section{Continued}

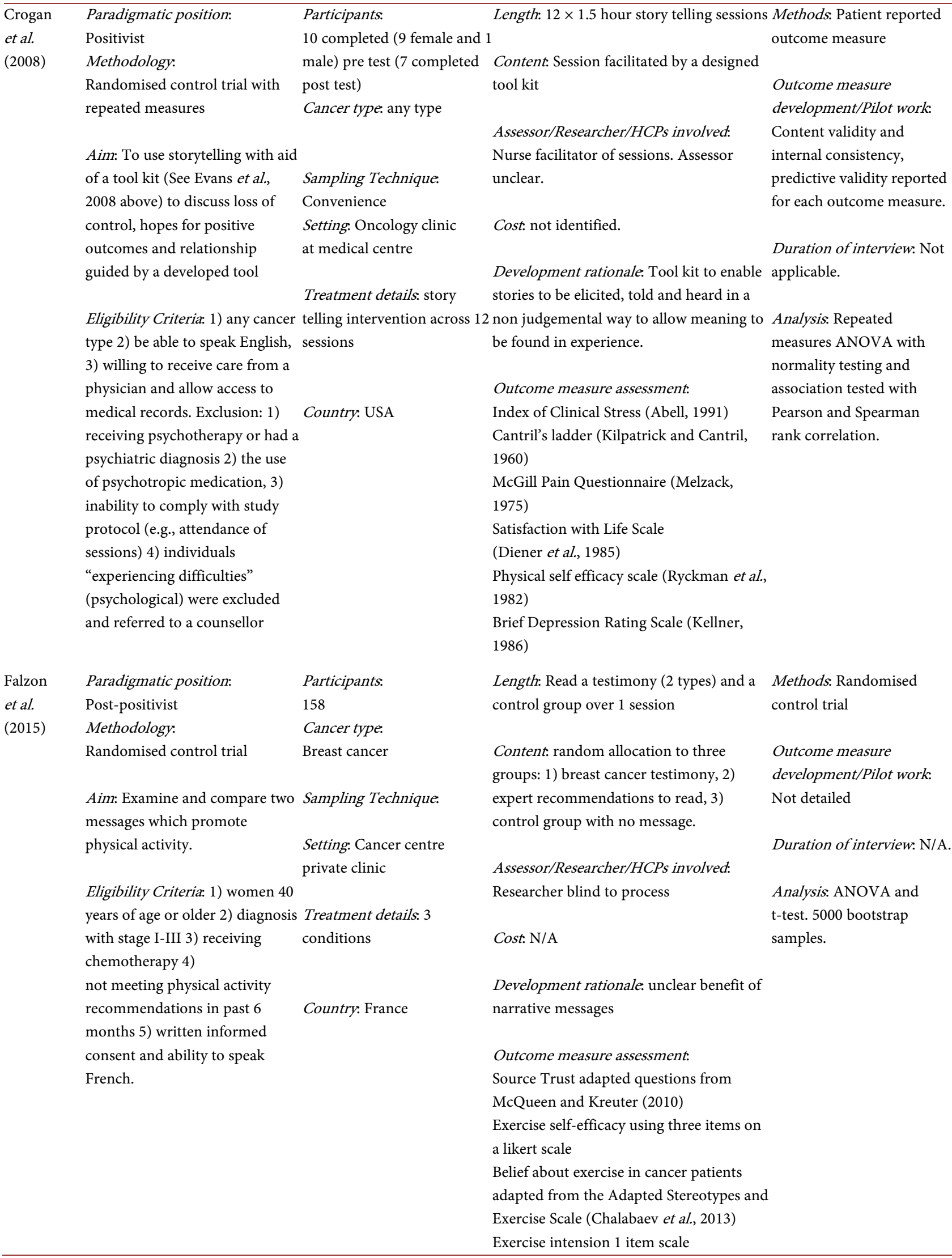




\section{Continued}

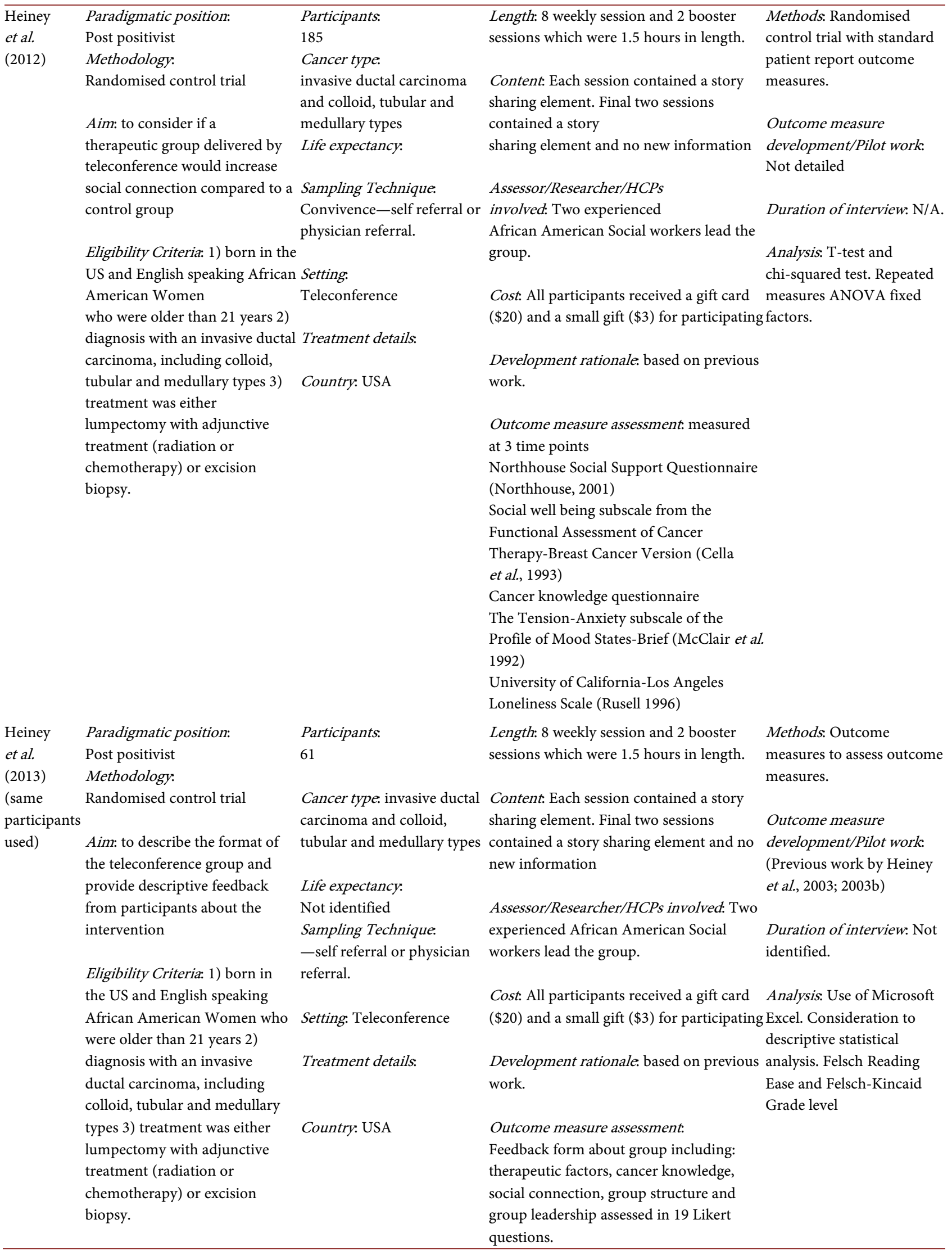




\section{Continued}

\begin{tabular}{|c|c|c|c|c|}
\hline Heiney & Paradigmatic position: & Participants: & Length: 8 weeks then every 2 weeks for 3 & Methods: \\
\hline et al. & Post positivist & 168 & years & \\
\hline$(2015)$ & Methodology: & Intervention group 55.4 & & Outcome measure \\
\hline (same & Randomised control trial & $(11.0)$ years & Content: Randomisation into story & development/Pilot work: \\
\hline participants & & Control group & intervention group or psychosocial care & \\
\hline used) & Aim: consider if depression and & $56.7(11.0)$ years & (active control group). Control group & Duration of interview: N/A \\
\hline & fatigue decrease more in the stor & y Cancer type: & received normal care and could request & \\
\hline & intervention group compared to & & any care within standard treatment. & Analysis. Wilcoxon signed \\
\hline & a control group & Sampling Technique: & & rank test due to skewed \\
\hline & & Convivence & Assessor/Researcher/HCPs & data \\
\hline & Eligibility Criteria: 1) 21 years & & involved: two social workers facilitated the & \\
\hline & old or older, African-American, & Setting: & session, in 15 sets of 10 participants. & \\
\hline & English Speaking, Diagnosed & Teleconference & & \\
\hline & with invasive ductal carcinoma & & Cost: Stipends given to participants & \\
\hline & within the previous 6 months. & Treatment details: & $\$ 3-\$ 10$ dollars & \\
\hline & & teleconference & Development rationale: & \\
\hline & & & participation in a group brings on benefits & \\
\hline & & Country: USA & for individuals where sharing is possible & \\
\hline & & & with others who are similar. & \\
\hline & & & Outcome measure assessment: & \\
\hline & & & $\begin{array}{l}\text { POMS-Short form (PMS-SF) (McNair et } \\
\text { al., 1992) }\end{array}$ & \\
\hline
\end{tabular}

Table S2. The completed 13-item COREQ framework (Soundy et al., 2016) adapted from the 32-item COREQ framework (Tong et al., 2007).

\begin{tabular}{|c|c|c|c|c|c|}
\hline \multicolumn{3}{|c|}{ Domain 1: Research team and reflexivity } & \multirow[t]{2}{*}{$\begin{array}{l}\text { Evans et al. } \\
2008\end{array}$} & \multirow[t]{2}{*}{$\begin{array}{l}\text { Høybye et al., } \\
2005\end{array}$} & \multirow[t]{2}{*}{$\begin{array}{l}\text { La Cour et al. } \\
(2016)\end{array}$} \\
\hline & onal Characteristics & Scoring & & & \\
\hline 1 & $\begin{array}{l}\text { Interviewer/facilitator Which } \\
\text { author/s conducted the interview } \\
\text { or focus group? }\end{array}$ & $\begin{array}{l}\text { If they have identified give a point, if they haven't } \\
\text { give } 0 \text {, if you unclear type } U \text {. }\end{array}$ & $\begin{array}{l}\text { U } \\
\text { Unclear who did } \\
\text { the interview }\end{array}$ & $\begin{array}{l}\text { U it says we a lot } \\
\text { but doesn't let the } \\
\text { reader know who }\end{array}$ & \\
\hline 2 & $\begin{array}{l}\text { Experience and training. What } \\
\text { experience or training did the } \\
\text { researcher have? }\end{array}$ & $\begin{array}{l}\text { Where experience is clearly detailed or a detailed } \\
\text { reference to training OR experience is made a } \\
\text { point is given. IF unclear or absent give zero. }\end{array}$ & $\begin{array}{l}0 \\
\text { As above }\end{array}$ & $\begin{array}{l}0 \text { No detail on } \\
\text { experience given }\end{array}$ & 1 \\
\hline \multicolumn{6}{|c|}{ Relationship with participants } \\
\hline 3 & $\begin{array}{l}\text { Relationship established, Was a } \\
\text { relationship established prior to } \\
\text { study commencement? }\end{array}$ & $\begin{array}{l}\text { Give a point if details of how the researcher or } \\
\text { person who undertook qualitative data collection } \\
\text { met individuals, identified any previous } \\
\text { relationship. Where this is unclear type U. Where } \\
\text { this information is absent type } 0 .\end{array}$ & $\begin{array}{l}0 \\
\text { Not mentioned }\end{array}$ & $\begin{array}{l}\text { U doesn't } \\
\text { consider how } \\
\text { relationship was } \\
\text { established after } \\
\text { initial contact }\end{array}$ & 1 \\
\hline 4 & $\begin{array}{l}\text { Participant knowledge of the } \\
\text { interviewer. What did the } \\
\text { participants know about the } \\
\text { researcher? e.g. personal goals, } \\
\text { reasons for doing the research }\end{array}$ & $\begin{array}{l}\text { A point is scored where information about what } \\
\text { the participants knew about the research they were } \\
\text { being invited to participate in was mentioned. This } \\
\text { includes sending background information and } \\
\text { study information sheets. Score zero where this } \\
\text { information is absent and } U \text { where this } \\
\text { information is unclear }\end{array}$ & 0 Not mentioned & $\begin{array}{l}1 \text { Research } \\
\text { information sent } \\
\text { to group giving } \\
\text { background } \\
\text { information. }\end{array}$ & \\
\hline 5 & $\begin{array}{l}\text { Interviewer characteristics. What } \\
\text { characteristics were reported } \\
\text { about the interviewer/facilitator? } \\
\text { e.g. Bias, assumptions, reasons } \\
\text { and interests in the research } \\
\text { topic }\end{array}$ & $\begin{array}{l}\text { Score a point where information about the } \\
\text { characteristics of the interviewer, their bias, } \\
\text { interests or reasons for participating in research } \\
\text { are identified. Score zero where this information is } \\
\text { absent. Score u where this information is unclear. }\end{array}$ & Not mentioned & 0 Not mentioned & 0 \\
\hline
\end{tabular}




\section{Continued}

\section{Total Score for Domain 1.}

Domain 2: study design

\section{Theoretical framework}

Methodological orientation and theory. What methodological orientation was stated to

6 underpin the study? e.g. grounded theory, discourse analysis, ethnography, phenomenology

Non-participation. How many 7 people refused to participate or dropped out? Reasons?
Score a point where the paradigm and methodology are given. Score zero where both aspects are missing. Score $U$ where this information is unclear.

Score a point where the number and the reason or attempts to identify the reason are given (e.g., a point is score if they say participants would not give a reason for non-participation). Score zero where this information is absent and score $\mathrm{u}$ where this information is unclear.
0.No mention of information 0.No needed
.No consideration
1.1 numbers 1 .

Clear numbers refusing to Clear numbers are identified with participate are are identified with reasons. given. reasons

Data collection

Score a point where testing of the interview script 0 . No reference to Interview guide. Were questions, is identified either as a pilot or as a way to development of 8 prompts, guides provided by the determine the content and accuracy of items used. the unstructured authors? Was it pilot tested? Score a point where consideration to the derivation interviews was of questions have come from. made. based on "topics with no specific sample questions" $\mathrm{U}$ it was developed from field material.

U highlights importance of

Field notes-Were field notes or reflective diary made during and/or after the interview or focus group?

Score a point where field notes are identified. Score zero where field notes are not identified. Score U where this information is unclear.

. No mention of field notes but no details to a field 1 . Field notes diary or evidence included. in results of the use of one.

Score a point where saturation of data is considered. Score a point where another form of sample size reference is made. Score $\mathrm{U}$ where this information is unclear. field notes. saturation discussed?
10 Data saturation. Was data

Total for Domain 2

$\begin{array}{ll}0 . \text { No mention of } & 0 . \text { No menti } \\ \text { sample size } & \text { sample size }\end{array}$

$1 / 5$
$1 / 5$
$2 / 5$

Domain 3: analysis and findings

Data analysis

Description of the coding tree.

11 Did authors provide a description of the coding tree?

Derivation of themes Were

12 themes identified in advance or derived from the data?
Score a point if an audit trail is given. Score a point if a coding tree is mentioned or score a point if another technique is mentioned that provides a way to structure the information gained.

Score a point if data driven or theory driven coding is identified or if it is clear how analysis was determined.
0 No detail given 0 No detail given 0 No detail given

1. Framework mentioned.
0 No detail given 1.Detail given

Reporting

Clarity of minor themes Is there Score a point if there is sub-detail for each major

13 a description of diverse cases or theme. Score no points where this information is discussion of minor themes?

absent or $\mathrm{u}$ if this information is unclear.

Total for domain 3

\section{Subthemes given}

$2 / 3$

$3 / 13$
U clear no real breakdown of $\mathrm{U}$. categories

$2 / 13$ $5 / 13$ 
Table S3. Identifying the quality of qualitative research.

\begin{tabular}{|c|c|c|c|c|c|}
\hline Area & Area & Questions to answer & Evans et al. 2008 & Høybye et al., 2005 & La Cour et al. (2016) \\
\hline \multirow[t]{2}{*}{ Clarification } & $\begin{array}{l}\text { What are the aims of } \\
\text { the research? }\end{array}$ & $\begin{array}{l}\text { Assess theoretical rigour } \\
\text { (soundness and fit of } \\
\text { question). Questions to } \\
\text { address: } \\
\text { Do the methods link to the } \\
\text { question well and are the } \\
\text { appropriate? }\end{array}$ & $\begin{array}{l}\text { Question is } \\
\text { appropriate and links } \\
\text { well to the methods } \\
\text { undertaken. }\end{array}$ & $\begin{array}{l}\text { Question is } \\
\text { appropriate and links } \\
\text { well to data gained. }\end{array}$ & $\begin{array}{l}\text { Question is appropriate } \\
\text { and links well to data } \\
\text { gained. }\end{array}$ \\
\hline & $\begin{array}{l}\text { What is the research } \\
\text { question? }\end{array}$ & $\begin{array}{l}\text { Is the question appropriate } \\
\text { and does it contain all } \\
\text { elements you would expect? }\end{array}$ & $\begin{array}{l}\text { All elements of the } \\
\text { question are given } \\
\text { except outcome } \\
\text { measure focus }\end{array}$ & All elements provided. & All elements provided \\
\hline \multirow[t]{2}{*}{ Justification } & $\begin{array}{l}\text { Why is a qualitative } \\
\text { approach the best } \\
\text { option to answer this } \\
\text { question? }\end{array}$ & $\begin{array}{l}\text { Does the justification } \\
\text { include the paradigmatic } \\
\text { considerations and } \\
\text { methodological } \\
\text { considerations and the } \\
\text { rationale given? }\end{array}$ & $\begin{array}{l}\text { Justification based on } \\
\text { background literature } \\
\text { and theory. }\end{array}$ & $\begin{array}{l}\text { Justification based on } \\
\text { the need to consider } \\
\text { social relationships in } \\
\text { action expressed } \\
\text { through narrative. }\end{array}$ & $\begin{array}{l}\text { Follow on from past } \\
\text { ethnographic work }\end{array}$ \\
\hline & $\begin{array}{l}\text { Why was the particular } \\
\text { qualitative research } \\
\text { design chosen? }\end{array}$ & $\begin{array}{l}{ }^{\mathrm{r}} \text { Has a rationale been } \\
\text { provided? }\end{array}$ & $\begin{array}{l}\text { Rationale for why } \\
\text { qualitative and not } \\
\text { quantitative research is } \\
\text { not given }\end{array}$ & $\begin{array}{l}\text { To be embedded in a } \\
\text { setting. }\end{array}$ & $\begin{array}{l}\text { To answer the selected } \\
\text { question }\end{array}$ \\
\hline \multirow[t]{2}{*}{ Procedural rigour } & $\begin{array}{l}\text { Have the techniques of } \\
\text { data collection been } \\
\text { clearly documented? }\end{array}$ & $\begin{array}{l}\text { Has the following been } \\
\text { consider: accessing } \\
\text { participants, development } \\
\text { access, development of } \\
\text { rapport and trust, } \\
\text { identification of data } \\
\text { collection, recording, } \\
\text { coding and analysing. Does } \\
\text { it consider how refusal to } \\
\text { participate is addressed? }\end{array}$ & $\begin{array}{l}\text { Access information } \\
\text { could be clearer and } \\
\text { development of } \\
\text { rapport not given. } \\
\text { Framework to avoid } \\
\text { analysis provided. }\end{array}$ & $\begin{array}{l}\text { Clear information } \\
\text { about access, } \\
\text { development of access, } \\
\text { development of } \\
\text { rapport are provided. } \\
\text { Refusal to participate is } \\
\text { considered. }\end{array}$ & $\begin{array}{l}\text { Clear information } \\
\text { about access, } \\
\text { development of access, } \\
\text { development of } \\
\text { rapport are provided. } \\
\text { s Refusal to participate is } \\
\text { considered. }\end{array}$ \\
\hline & $\begin{array}{l}\text { Are the forms of data } \\
\text { analysis completely } \\
\text { transparent? }\end{array}$ & $\begin{array}{l}\text { How was the data managed } \\
\text { is an audit trail provided of } \\
\text { the processes undertaken? }\end{array}$ & No audit trail is given. & No audit trail is given. & No audit trail is given. \\
\hline \multirow[t]{2}{*}{ Representativeness } & $\begin{array}{l}\text { What sampling } \mathrm{t} \\
\text { echniques have been } \\
\text { used to answer the } \\
\text { research question? }\end{array}$ & & Not mentioned & Not mentioned & Not mentioned \\
\hline & $\begin{array}{l}\text { Do the sampling } \\
\text { techniques support } \\
\text { conceptual } \\
\text { generalisability? }\end{array}$ & $\begin{array}{l}\text { Do they mention a type? } \\
\text { Maximum variation-(all } \\
\text { aspect of the topic under } \\
\text { question?) } \\
\text { Homogenous (selection } \\
\text { fitting a particular criteria) } \\
\text { snowball or convenience } \\
\text { (perhaps weakest for } \\
\text { generalisability) }\end{array}$ & $\begin{array}{l}\text { Not mentioned likely } \\
\text { convenience. }\end{array}$ & $\begin{array}{l}\text { Not mentioned likely } \\
\text { convenience. }\end{array}$ & $\begin{array}{l}\text { Not mentioned likely } \\
\text { convenience }\end{array}$ \\
\hline
\end{tabular}


Continued

\begin{tabular}{|c|c|c|c|c|c|}
\hline \multirow[t]{2}{*}{ Interpretation } & $\begin{array}{l}\text { Has a more conceptual } \\
\text { discussion of the } \\
\text { results and linkage to } \\
\text { existing theory or new } \\
\text { theory been developed } \\
\text { to explain the } \\
\text { relevance of findings } \\
\text { to a targeted audience } \\
\text { or discipline? }\end{array}$ & $\begin{array}{l}\text { l Consideration to those } \\
\text { involved in the process } \\
\text { (research triangulation) } \\
\text { Consideration to member } \\
\text { checking been made? } \\
\text { Triangulation of data } \\
\text { sources? OR methods OR } \\
\text { theory? }\end{array}$ & $\begin{array}{l}\text { Blind analysis was } \\
\text { undertaken and } \\
\text { agreement between } \\
\text { two reviewers was } \\
\text { assessed. }\end{array}$ & $\begin{array}{l}\text { Lack of clarity around } \\
\text { the analysis }\end{array}$ & $\begin{array}{l}\text { Triangulation of me- } \\
\text { thods was } \\
\text { undertaken }\end{array}$ \\
\hline & $\begin{array}{l}\text { Have any negative } \\
\text { cases been included } \\
\text { and discussed? }\end{array}$ & & Not identified. & Not identified. & Not identified. \\
\hline \multirow[t]{3}{*}{$\begin{array}{l}\text { Reflexivity and } \\
\text { evaluative rigour }\end{array}$} & $\begin{array}{l}\text { Has a clear statement } \\
\text { of the effect on the } \\
\text { data of the researcher's } \\
\text { views and the methods } \\
\text { chosen been included? }\end{array}$ & & $\begin{array}{l}\text { No clear statement is } \\
\text { made. }\end{array}$ & $\begin{array}{l}\text { Yes consideration to } \\
\text { this is made. }\end{array}$ & $\begin{array}{l}\text { Yes consideration to } \\
\text { this is made. }\end{array}$ \\
\hline & $\begin{array}{l}\text { Has an explicit } \\
\text { evaluation of the } \\
\text { relationship between } \\
\text { the researcher and } \\
\text { those under research, } \\
\text { addressing any ethical } \\
\text { issues, been discussed? }\end{array}$ & $\begin{array}{l}\text { Ethical approval been } \\
\text { mentioned, steps taken to } \\
\text { avoid adverse effects on } \\
\text { individuals. Others } \\
\text { consulted in the design of } \\
\text { the research }\end{array}$ & $\begin{array}{l}\text { Ethical approval not } \\
\text { clearly identified. }\end{array}$ & $\begin{array}{l}\text { Ethical considerations } \\
\text { identified. }\end{array}$ & $\begin{array}{l}\text { Ethical considerations } \\
\text { identified. }\end{array}$ \\
\hline & $\begin{array}{l}\text { Has ethics approval } \\
\text { been obtained from an } \\
\text { appropriate } \\
\text { institution? }\end{array}$ & & $\begin{array}{l}\text { Ethical approval not } \\
\text { clearly identified. }\end{array}$ & Ethical approval gained & Ethical approval gained \\
\hline \multirow[t]{2}{*}{ Transferability } & $\begin{array}{l}\text { Has a critical } \\
\text { evaluation of the } \\
\text { application of findings } \\
\text { to other similar } \\
\text { contexts been made? }\end{array}$ & $\begin{array}{l}\text { What context and setting } \\
\text { information is provided and } \\
\text { how similar is that to other } \\
\text { settings? }\end{array}$ & $\begin{array}{l}\text { The setting Is a } \\
\text { regional medical } \\
\text { centre. No further } \\
\text { details are given. The } \\
\text { content of the } \\
\text { intervention is clear } \\
\text { and could be applied } \\
\text { elsewhere. }\end{array}$ & $\begin{array}{l}\text { The setting was an } \\
\text { online setting. }\end{array}$ & $\begin{array}{l}\text { The setting was in a } \\
\text { residential } \\
\text { rehabilitation location }\end{array}$ \\
\hline & $\begin{array}{l}\text { Has the relevance of } \\
\text { these findings to } \\
\text { current knowledge, } \\
\text { policy, and practice or } \\
\text { to current research } \\
\text { been discussed? }\end{array}$ & & Yes. & Yes. & Yes \\
\hline
\end{tabular}

Table S4. The summary assessment of the overall risk of bias for quantitative studies.

\begin{tabular}{|c|c|c|c|c|c|c|c|c|}
\hline \multirow[t]{2}{*}{ Trial $^{*}$} & \multicolumn{6}{|c|}{$\begin{array}{l}\text { Components of risk of } \\
\text { bias/key risk criteria }\end{array}$} & \multirow[t]{2}{*}{$\begin{array}{l}\text { Summary } \\
\text { within trial }\end{array}$} & \multirow[t]{2}{*}{ Comments on high risk components-(explain briefly why) } \\
\hline & 1 & 2 & 3 & 4 & 5 & 6 & & \\
\hline $\begin{array}{l}\text { Crogan et al. } \\
(2008)\end{array}$ & $\mathrm{H}$ & $\mathrm{H}$ & $\mathrm{H}$ & $\mathrm{H}$ & $\mathrm{L}$ & $\mathrm{H}$ & $\begin{array}{l}\mathrm{H}=5 \\
\mathrm{~L}=1 \\
\mathrm{U}=0\end{array}$ & $\begin{array}{l}\text { Selection bias: No identification of sequent generation or allocation } \\
\text { concealment. } \\
\text { Detection/Performance bias: No blinding of assessors mentioned. } \\
\text { Other bias: No protocol. Choice of statistics questionable. }\end{array}$ \\
\hline
\end{tabular}




\section{Continued}

\begin{tabular}{|c|c|c|c|c|c|c|c|c|}
\hline $\begin{array}{l}\text { Garcia-Schinzari } \\
\text { et al. (2014) }\end{array}$ & $\mathrm{H}$ & $\mathrm{H}$ & $\mathrm{H}$ & $\mathrm{H}$ & $\mathrm{L}$ & $\mathrm{H}$ & $\begin{array}{l}\mathrm{H}=5 \\
\mathrm{~L}=1 \\
\mathrm{U}=0\end{array}$ & $\begin{array}{l}\text { Selection bias: No identification of sequent generation or allocation } \\
\text { concealment. } \\
\text { Detection/Performance bias: No blinding of assessors mentioned. } \\
\text { Other bias: No protocol. Choice of statistics questionable. Sample } \\
\text { size not justified }\end{array}$ \\
\hline $\begin{array}{l}\text { Falzon et al. } \\
(2015)\end{array}$ & $\mathrm{L}$ & $\mathrm{L}$ & $\mathrm{L}$ & $\mathrm{L}$ & $\mathrm{L}$ & $\mathrm{H}$ & $\begin{array}{l}\mathrm{H}=1 \\
\mathrm{~L}=5\end{array}$ & Other bias: No protocol. \\
\hline $\begin{array}{l}\text { Heiney et al. } \\
(2012)\end{array}$ & $\mathrm{H}$ & $\mathrm{H}$ & $\mathrm{L}$ & $\mathrm{L}$ & $\mathrm{L}$ & $\mathrm{H}$ & $\begin{array}{l}\mathrm{H}=3 \\
\mathrm{~L}=3\end{array}$ & $\begin{array}{l}\text { Selection bias: No identification of sequent generation or allocation } \\
\text { concealment. } \\
\text { Other bias: No protocol. Sample size not considered. }\end{array}$ \\
\hline $\begin{array}{l}\text { Heiney et al. } \\
\text { (2013) }\end{array}$ & $\mathrm{H}$ & $\mathrm{H}$ & $\mathrm{L}$ & $\mathrm{L}$ & $\mathrm{L}$ & $\mathrm{H}$ & $\begin{array}{l}\mathrm{H}=3 \\
\mathrm{~L}=3\end{array}$ & $\begin{array}{l}\text { Selection bias: No identification of sequent generation or allocation } \\
\text { concealment. } \\
\text { Other bias: No protocol. Sample size not considered. Refers to } \\
\text { Heiney et al. (2012) for procedures and methods. }\end{array}$ \\
\hline $\begin{array}{l}\text { Heiney et al. } \\
\text { (2015) }\end{array}$ & $\mathrm{H}$ & $\mathrm{H}$ & $\mathrm{L}$ & $\mathrm{L}$ & $\mathrm{L}$ & $\mathrm{H}$ & $\begin{array}{l}\mathrm{H}=3 \\
\mathrm{~L}=3\end{array}$ & $\begin{array}{l}\text { Selection bias: No identification of sequent generation or allocation } \\
\text { concealment. } \\
\text { Other bias: No protocol. Sample size not considered. Refers to } \\
\text { Heiney et al. (2012) for procedures and methods. }\end{array}$ \\
\hline
\end{tabular}

${ }^{*}$ Trial denoted by first author. Risk of bias criteria: 1, Selection bias = random sequence generation; 2, selection bias = allocation concealment; 3 , Detection/Performance bias = blinding of personnel, assessors and participants; 4, Attrition bias = incomplete outcome data; 5, Reporting Bias = short-term selective outcome reporting; 6 , Other bias = potential threats to validity e.g., consideration of a protocol. Levels of risk of bias: $\mathrm{H}$, high risk of bias; $\mathrm{U}$, unclear risk of bias; $\mathrm{L}$, low risk of bias.

Table S5. Synthesis stage 1 showing an example of the qualitative tabulisation.

\begin{tabular}{|c|c|c|}
\hline Study & Results & Comments by AS \\
\hline $\begin{array}{l}\text { Evans } \\
\text { et al. } \\
\text { (no 3) }\end{array}$ & $\begin{array}{l}\text { The patterns were Finding a soft Place to Fall, in which the individual finds } \\
\text { meaning in life while reawakening compassion and caring on the spiritual } \\
\text { journey; understanding the cancer Experience, in which the individual } \\
\text { understands and transforms suffering, deepening understanding and } \\
\text { acceptance of the life cycle and death; and Figuring Out How (if) to get } \\
\text { Through it: coping and not coping, in which the individual heals relationships } \\
\text { with self and others (see Table 1). } \\
\text { Although the storytelling group was comprised of only three participants who } \\
\text { completed the 12-week session (com-pared to four participants in the control } \\
\text { group), the storytellying group produced a wider variety of themes relating to } \\
\text { Watson's (2002) tasks under the Finding a soft Place to Fall and } \\
\text { understanding the cancer Experience patterns. Figuring Out How (if) to get } \\
\text { Through it was subdivided into coping and not coping themes. Although both } \\
\text { groups could describe coping using internal mechanisms (i.e., coping } \\
\text { strategies focused on intrapersonal resources) and external mechanisms (i.e., } \\
\text { coping strategies focused on outside resources), not coping themes displayed } \\
\text { some differences. For example, when asked to describe what not coping looks } \\
\text { like, the storytelling group listed a wider variety of internal mechanisms that } \\
\text { were characteristic of failure to cope than did the control group. The only } \\
\text { external mechanism indicative of not coping was identified by the control } \\
\text { group: "running to the doctor if you feel something different and you think it } \\
\text { might be cancer again." That finding may indicate increased insight in the } \\
\text { storytelling group as to the differences between effective and ineffective } \\
\text { coping (see Table 2). } \\
\text { The storytelling group believed that they could share their feelings and feel } \\
\text { accepted and secure, despite low energy levels. The group also articulated a } \\
\text { broader range of themes, indicating understanding of the cancer experience, } \\
\text { and described more fully what not coping looked like. That may indicate that }\end{array}$ & $\begin{array}{l}\text { Benefit: increased Knowledge/Understanding cancer } \\
\text { experience } \\
\text { Benefit: understanding or sharing coping related stories } \\
\text { Control group: in contrast more uncertainty } \\
\text { Impact and consideration to the social aspects }\end{array}$ \\
\hline
\end{tabular}


they were better acquainted with, or had more insight into, not coping compared to the control group. The control group articulated the only feelings of uncertainty about expectations of the group experience; although they were glad to blend into the crowd, they felt they could be truthful and still be accepted and supported.

Finding a Soft Place to Fall

Storytelling group: The tool kit required self-disclosure by the nurse facilitator and sharing personal information with participants through stories as a means of role-modeling trust. In terms of Watson's (2003) framework, the facilitator suspended her usual role as an authority figure to become vulnerable and acknowledge her own humanity. such self-disclosure on the part of the nurse facilitator helped one participant feel less vulnerable and more understood, rather than analyzed. "it was like my own personal therapy session, only better because you shared your experience, too." Another was thankful that she had found a place to openly discuss her fears about her cancer diagnosis; she was not allowed to do so at home because her husband strictly believed in positive thinking.

The facilitator was instructed to allow stories to come forth as group members Danger of storytelling and sharing: Potential negative chose to tell them, instead of pursuing the stories she wanted them to tell. She outcome the way or freedom or uncontrolled nature of was cautioned that revisiting past experiences could evoke pain and that making private memories public may not be easy. Based on the interviews and Group creates a space of vulnerability-not everyone wants questionnaires, the nurse facilitator was able to let participants "choose what to share but may feel safe, then regret it they wished to remember and tell ... and participate in negotiating the context of remembering" (Errante, 2000, p. 19). She also was instructed to avoid gatekeeping that could shut off stories as they began to surface. She countered this by allowing members to each "have their night" if they were severely stressed, emphasizing that the same courtesy would be extended to others as needed.

Those strategies were reflected in two outliers defined by miles and Huberman (1994) as exceptions to the rest of the qualitative data. Such exceptions alert the researcher to guard against bias and help to refine a construct or test generalities that seem to emerge from the data. Although others felt safe in the group, one participant shared some private information despite considering herself "not the type of person to share personal feelings." she reported that this information was later revisited in a joking manner within the group. “i didn't feel i had the freedom to say that i didn't appreciate that ... but it showed me that you have to still be very careful." The participant also expressed conflicting thoughts about the way the storytelling group was run.

Where one person monopolizes the group ... whether that person should have been controlled or whether it was good because the person knew they'd be helped. I still haven't quite figured that out because I saw the person change considerably from when they first started the group. The evidence underscores the importance of creating a soft Place to Fall an possible need for additional facilitator training and participant teaching. The
participants' conflicting thoughts, however, acknowledged the deliberate lack of gatekeeping and questioned whether it was helpful to other group members. The statements of exception were useful during analysis because they provided evidence that the nurse facilitator had avoided gatekeeping as instructed, as well as evidence of a possible therapeutic outcome for the participant undergoing change. Also indicated was a beginning acceptance by the woman who provided the outlier statements that, when the "monopolizer" worked to heal herself in the context of the group, she "contributed to the healing of the whole" (Watson, 2003, p. 201).

Silences in the group were documented as natural and comfortable. Group members appeared to reflect on or con template stories just disclosed. This is typical of transpersonal caring activities (Watson, 2003).

Control group: self-disclosure by the leader is somewhat unusual in traditional group process when the leader usually is focused on keeping the

Facilitator of social interaction: HCP sharing personal information-suspended normal role.

Benefit of open sharing of difficult topics-like fears

Activity is self-directed, content self-selected making for a powerful participant led session

Intervention allowed a voice to different types of suffering, provided a platform for those who were distressed to talk plainly

Danger of the group-monopoly by one person-could silence other

Benefit - the ability to freely express was observed to be healing

Training requirement for such a group

Social comparison as a direct benefit: The person working through challenges, overcoming obstacles or being able to mentally, emotionally or behaviourally change during the group could be inspiring and allow others to do the same.

Possible area for influencing results - technique of

facilitator same as story group.

Key differences printed information 
group on track with the agenda, gatekeeping to prevent monopolizing of the session by one person, or analyzing and probing coping strategies. The social worker facilitator, however, unexpectedly used self-disclosure to encourage group members to reveal personal information, paralleling the storytelling group facilitator's technique.

Control group activities emphasized education with a guest speaker and distribution of printed materials. Debriefing questionnaires showed that participants continued to look strongly to the facilitator for guidance, despite her efforts to shift the leadership to group members. Silences occurred on several occasions and were described as peaceful but uncomfortable. How participants expressed their appreciation for the caring they found in the group and consistently treated one of the quieter women with affection, reflecting that they experienced her quietness as "patience and strength." Understanding the Cancer Experience

Storytelling group: The nurse facilitator was able to avoid judging, analyzing, and extracting data from the stories and seemed to accept them as whole and true to the teller, as instructed (Watson, 2003). She avoided probing discussions on coping strategies but worked to get in touch with participants through an interpersonal bridge created, in part, by her own self-disclosure (Errante, 2000; Watson, 2003). Those strategies were aimed at producing "virtually shared experiences" (Errante, p. 24) that allowed group members to vicariously enter the storytellers' realities and work toward shared meaning (Watson, 2003).

To suspend role and status (Watson, 2003), the nurse facilitator initially informed the group that she considered them to be the experts on the cancer journey. Subsequently, she was treated more like a group member than as a leader, with participants telling and retelling their stories to one another as they worked to make meaning from the cancer experience. Frequent retelling Process: being able to express suffering and illustrate pain, may have occurred because stories allow people to forget and reinvent certain the journey and challenge faced aspects of their pasts, making them more acceptable in current circumstances (Errante, 2000). The stories often need to be reexplored for meaning in light of what participants now know. Revised versions then are used to validate identities and suffering, for both the participant and the group. Such validation was appreciated by one woman who said, "The group helped me see that the things that were happening weren't because of a failure on my part or something i had done wrong, or not done."

Other evidence of implementation of the storytelling tool kit was noted in participants' visible and frequent use of storytelling as they sought to discover meaning (leight, 2002). Their stories acknowledged that the cancer diagnosis requires the creation of a new map for their lives; that relationships with others are irretrievably altered; that bearing witness to the cancer story, despite its telling and retelling, is a healing gift (Watson, 2003); and that the medical narrative, chosen initially by both groups in this project as a way for members to tell their stories in an often-rehearsed, socially sanctioned format, Hope born out of shared suffering or unity cannot fully express the illness experience. The medical narrative, the short-hand technical language universally used by healthcare providers, furnishes an efficient way for patients to communicate to others about cancer. Unfortunately, this narrative may fail to consider how cancer is experienced or to honor the differences in healing journeys (Watson, 2003). The nurse facilitator was cautioned about reliance on such narratives and was able to guide participants in telling their own personal stories of illnesses.

Attention to individual patient suffering was provided by exploration of the stories and not the clinical stories of the disease process (Emblen \& Pesut, 2001). As the group worked together to understand their suffering, one woman was "faced with the fact that i might live, then what?" despite many family members dying of the disease. That realization changed her suffering and she "started dancing again. i gave it up for three years!" Another woman referred to an essay by Kingsley (2001) and likened her cancer diagnosis to a trip to italy (her metaphor for health and wellness). She talked about her
2) Avoidance of probing

3) importance of entering and hearing anothers world and developing shared meaning

4) distance created of being an expert-told participants they are the experts

5) allowance for retelling of stories-or re-explored for meaning and meaning making

6) validation of suffering

7) consideration of social identity and impact of cancer on er,that identity

Benefit-not being too hard on themselves—group help individual see that they personally hadn't done anything wrong in situations-they hadn't failed

Group can introduce hope, collective experience may provide different ways to see the future

Outcome: impact on activities e.g., dancing

Process: group provides different ways to express by using others stories as a mechanism for positive change

Outcome/process: ability to share vulnerability, resentment. Ability to be 'real' with others

Process for effective outcome is shared understanding of the disease

Mechanism for benefit: no need for the group to fix the problems that are shared just live with them

Outcome: Reaffirming a sense of self or social identity or shared identity that is how they define themselves. 
excited anticipation and preparations for the trip; but when the plane landed, Shared difficulties: experiences of not being who they once she was in Holland. she suffered: she was lost, cold, and unable to communicate with others but she did the best she could on the unanticipated journey. Others entered into her metaphor for suffering, saying, "it's Holland, Recognition of life in the present what it looks like and and i don't like tulips!" "i'm stuck and i can't read the map," and "i'd rather besharing that in italy with my friends!" They told stories about the loss of familiar, beloved things; shared their sense of vulnerability; and expressed resentment at lost companionship. But then one said, "Well, I'm going to italy as well," which led to stories about self-pity and how counterproductive it was to the daily business of living.

Control group: The aim of the control group was to foster participants' coping abilities and to provide social support and information on cancer treatment. Participants occasionally told stories in response to questions about their health (Sandelowski, 1994), but they usually used the medical narrative. Unlike the nurse facilitator in the storytelling group, who avoided breaking stories apart to analyze them, the social worker facilitator used traditional group process techniques such as extracting and analyzing aspects from each participant's contribution for discussion. However, participants expressed relief at finding others who understood the fears and pain of cancer

diagnosis and treatment (perhaps a precursor to recognizing the importance of bearing witness to others' suffering, if guidance had been available), as well as an opportunity to gain information about the disease. Patients sometimes mentioned their own personal experiences with cancer, although a difference between their stories and the medical narrative was not recognized. One such occurrence focused on hope, and the participants offered their own symbols for hope, expressed hope for effective treatment, and asked that a candle be lit "to give us spirit."

Figuring Out How (If) to Get Through It: Coping and Not Coping Storytelling group: group members discussed bearing witness to each other's stories with the guidance of the nurse facilitator, recognizing that it was not about fixing the issue or even having something to say, but just being with people (Quinn, Smith, Ritenbaugh, Swanson, \& Watson, 2003), acknowledging who they were, and reminding them that their disease did not define or tarnish them. They talked about life, hope, and fear in the context of their personal narratives of the cancer experience: "custody of my grandchild who needed the normal, healthy parent in me," "watching a plant grow under my nurturing care," "living what is today," "fear of suffering, not of dying," and "someone bearing witness to your life." Two women, however, had difficulty determining how to proceed; one felt stuck in a victim role and could not see past that (although she held out hope for the future), and another reported that her skin burned from radiation and that she had feelings of depression. Control group: group members tearfully discussed getting through the cancer journey with strengths they had not known they possessed prior to their diagnoses and were pleased with their ability to contribute to the project, although one woman found it difficult to live with uncertainty. They offered support to other group members undergoing crises such as divorce and scans to restage their cancer, occasionally sharing a group hug at the end of a session. One interesting dichotomy that surfaced was how they pointed out the need for understanding of each person's unique story. One participant chose to worry only if the cancer actually recurred, whereas another chose to worry about the possibility of it recurring.

Experiences of Oncology Nurses Associated With the Project

Oncology nurses from a regional medical center were recruited to participate in this project. Despite their workloads and family responsibilities, facilitators and research assistants were willing to participate. The nurses expressed interest in any technique that would ease the suffering of patients with cancer, particularly inexpensive strategies with little risk to patients. Some nurses asked to attend the sessions even though they could not be part of the project

Outcome: no change, not able to get past the impact of pain, or depression experienced

Element of the control group which is similar or crosses over with the intervention group

Outcome recognition by other stakeholders of the ability of sharing stories to limit or ease suffering 
because they wanted to learn skills they could use in their own practices. The medical center provided support so that nurses could receive training, during and after the project.

The nurses involved went on to incorporate storytelling techniques into their daily practices, even if only for a moment during a hectic day, and expressed appreciation for their increased abilities to ease suffering. The nurse who took primary responsibility for facilitating the storytelling group reported a profound change in her nursing care and expressed hope that more nurses be given the opportunity to learn the techniques.

Limitations

The study included a small number of participants. A larger study would provide a greater understanding of the efficacy of storytelling groups. Also, the results of this study do not indicate whether the tool kit alone would be sufficient instruction. Perhaps the eight hours of training are vital, but a programmed instruction format could be used to present the principles and protocol in successive units followed by self-testing. Such instruction could include a videotape or slide presentation of a teacher discussing the materials or be presented in an interactive online format. Future studies could incorporate such training for facilitators and test for achievement of educational outcomes.

Table S6. Synthesis stage 2 an example of the descriptive analysis undertaken.

\begin{tabular}{lll}
\hline Study Results Comments by AS & Com
\end{tabular}

\section{Results}

3.1. Description of children's and adolescent's behavior during practice

According to the analysis of children's and adolescents' behavior records, four categories

of analysis and eight subcategories (in parentheses) were identified: interaction with people (interaction with pairs of Occupational Therapy graduates and interaction with their peers); interaction with materials (manipulation of the objects of the box and participation in the accomplishment of the proposed activity); cognitive abilities (attention in history and imagination); and motivation (animation and curiosity awakened by history).

As for interaction with people, it was verified when the children/adolescents questioned and answered the questions of the graduates and family members, interacted with other children/adolescents, showed the activities performed for team members or other people and talked about their daily lives. Interaction with the couple of undergraduates occurred for $90 \%$ of the children/adolescents and the interaction with other children/adolescents, for only $30 \%$ of the participants.

The interaction with materials was observed when the children/adolescents used the objects of the box to show to other people, to retell the story with their words or to invent another story, besides helping the couple of undergraduates at the end of the

(2014) intervention, and $80 \%$ of the children/teenagers manipulated the objects in the box (right after the storytelling by the pair of graduates). It was observed that $90 \%$ of the children/adolescents were involved in the play activity proposed after the exploration of the materials of the box, performing activities such as painting, confection of objects and collage. As for cognitive abilities, $100 \%$ of the children/adolescents maintained their attention in history, a fact observed through the attentive gaze in the staging and through the changes in the facial expression, coherent with the unfolding of the story, besides, it was noticed that they managed, later, recount the story properly. In relation to the imagination, it was observed in $30 \%$ of the children during the exploration of the materials and storytelling, Engagement in sharing through the use of the account during the representation of scenes and manipulation of the elements of the box (extrapolating the story to daily activities such as bathing, brushing teeth, eating) and/or adding new characters and scenarios.

As to motivation, $80 \%$ of the children/adolescents were animated and $60 \%$ showed curiosity. The animation was evidenced through smiles and excitement when retelling the story, in the manipulation of the materials and the interaction with the people present. Mechanism: Emotions could be one way stories The curiosity occurred through questions of the participants regarding the way of makingimpact people and create change in behaviour

Interaction with people as an important outcome to compare across groups

Engagement in sharing as an activity as a possible point of comparison

En 
the box and the characters, ways to carry out the proposed activities, including other types of materials.

3.2. Feelings before and after storytelling

Impact of sharing in emotional outcomes. $45 \%$ increased to a more positive emotion from

As for the feelings of children and adolescents before and after the story was told, scores story telling

were assigned to the feelings expressed by them, the

which varied between 1 (Very sad), 2 (Sad), 3 (happy) and 4 (Very happy).

Of the 20 children/adolescents participating in the study, nine (45\%) changed to a

happier emotion, $10(50 \%)$ participants remained in the same category of emotion, all of Good interaction may explain positive change whom were already in a positive emotional state or very cheerful) and only one changed in emotions

to a sadder emotion (5\%) after the Story Box. The participant who remained in a sad

emotional state did not interact with other people and was not motivated during the Factor that influenced outcome: not wanting to practice. However, the participant who decreased his score, despite interacting with other share, not finding value in sharing or not people and being motivated, changed his emotional state from very cheerful to cheerful motivated to participate in sharing (from 4 to 3). Among the participants who improved their scores, $55 \%$ interacted with

the couple of undergraduates and/or with other children and adolescents and were The change is not negative-can everyone stay motivated (showing excitement and curiosity).

Analyzing the results before and after storytelling, it was possible to see that children and cheerful.

adolescents significantly modified their emotional state, with p value equal to 0.0111 , as can be seen in Table 1 :

Mechanism: interaction with others may be a

The results show that the scores are higher after the intervention with the Story Box. The facilitator of change exact test performed by the binomial distribution indicates a $p$ value of 0.0107 , that is, the median pre-intervention scores are significantly lower than the post-intervention scores. Result: Change in emotion significant higher View source for story group than control group

Bonding during play is important for the recovery of the child (MELO, 2003). During the development of this study, it was verified that the Box of Stories intervention allowed for Positive interaction within story telling as a a positive interaction between the graduates and the children and adolescents through explanation for increase in positive emotions dialogue about the stories told and about the making of the box during the exploration of materials and execution of activities, thus favoring socialization.

Table 1

\begin{tabular}{ccc}
\hline Feeling & Before & After \\
\hline Very happy & 8 & 13 \\
Happy & 7 & 4 \\
Sad & 3 & 3 \\
Very Sad & 2 & 0 \\
\hline
\end{tabular}

Table S7. Mind mapping.

\begin{tabular}{|c|c|c|c|}
\hline $\begin{array}{l}\text { Content of } \\
\text { interaction }\end{array}$ & $\begin{array}{l}\text { Outcomes } \\
\text { from groups }\end{array}$ & $\begin{array}{l}\text { Mechanisms which } \\
\text { explain benefit }\end{array}$ & $\begin{array}{l}\text { Factor which } \\
\text { influences benefit }\end{array}$ \\
\hline $\begin{array}{l}\text { Openness of sharing } \\
\text { personal lived experience }\end{array}$ & $\begin{array}{l}\text { Increased knowledge or } \\
\text { understanding of cancer }\end{array}$ & $\begin{array}{l}\text { Use of metaphor helped reframe } \\
\text { suffering-enabled learning - }\end{array}$ & $\begin{array}{l}\text { Space where openness is possible- } \\
\text { prevented in other interactions }\end{array}$ \\
\hline Use of humour & $\begin{array}{l}\text { Shared understanding of coping- } \\
\text { shared strategies }\end{array}$ & $\begin{array}{l}\text { Group can allow self-directed } \\
\text { content }\end{array}$ & Domination of one member of the group \\
\hline Real or lived interaction & & $\begin{array}{l}\text { Allows a space for emotions to be } \\
\text { expressed }\end{array}$ & Being able to express suffering \\
\hline Sharing loss & $\begin{array}{l}\text { Negative experience having shared } \\
\text { information used inappropriately }\end{array}$ & $\begin{array}{l}\text { Understanding of coping } \\
\text { behaviours increases }\end{array}$ & $\begin{array}{l}\text { Other stakeholders /Facilitator sharing } \\
\text { personal information-allowed or gave } \\
\text { permission to open up }\end{array}$ \\
\hline $\begin{array}{l}\text { Personal } \\
\text { difficulties revealed }\end{array}$ & $\begin{array}{l}\text { Increase in valuable /trusted } \\
\text { relationships }\end{array}$ & Lack of judgement given on any sharing & $\begin{array}{l}\text { Negative experience-not wanting to } \\
\text { share opening }\end{array}$ \\
\hline
\end{tabular}




\section{Continued}

\begin{tabular}{|c|c|c|}
\hline Hopes, fears, losses & Introduction of hope & Others feel really heard \\
\hline \multirow[t]{8}{*}{$\begin{array}{l}\text { How challenges } \\
\text { are overcome }\end{array}$} & Increase in activities & $\begin{array}{l}\text { Knowing someone else is } \\
\text { experience what they are going } \\
\text { through-validation of suffering }\end{array}$ \\
\hline & $\begin{array}{l}\text { Reaffirming a sense of } \\
\text { self and self identity }\end{array}$ & Decrease blame on themselves \\
\hline & Sense of control & No perceived need to fix problems \\
\hline & Impact on emotional well being & Reaffirming a sense of self and self identity \\
\hline & Social well being & Use of humour \\
\hline & Legitimise experiences & Unity in sharing \\
\hline & $\begin{array}{l}\text { Enhanced interactions, } \\
\text { activities or accomplishments }\end{array}$ & $\begin{array}{l}\text { Getting past stereotypes of others- } \\
\text { towards what their lives are like }\end{array}$ \\
\hline & & $\begin{array}{l}\text { Silence facilitated interaction, enabled } \\
\text { sharing, some were } \\
\text { unhappy with the silence }\end{array}$ \\
\hline
\end{tabular}

Table S8. Synthesis stage 3 the mind map.

\begin{tabular}{|c|c|c|c|}
\hline Content of interaction & Outcomes from groups & Mechanisms which explain benefit & Factor which influences benefit \\
\hline $\begin{array}{l}\text { Openness of sharing personal } \\
\text { lived experience }\end{array}$ & $\begin{array}{l}\text { Increased knowledge or understanding } \\
\text { of cancer }\end{array}$ & $\begin{array}{l}\text { Use of metaphor helped reframe } \\
\text { suffering-enabled learning- }\end{array}$ & $\begin{array}{l}\text { Space where openness is possible } \\
\text { - prevented in other interactions }\end{array}$ \\
\hline Use of humour & \multirow[t]{3}{*}{$\begin{array}{l}\text { Shared understanding of coping - shared } \\
\text { strategies }\end{array}$} & $\begin{array}{l}\text { Group can allow self-directed } \\
\text { content }\end{array}$ & $\begin{array}{l}\text { Domination of one member of } \\
\text { the group }\end{array}$ \\
\hline Real or lived interaction & & $\begin{array}{l}\text { Allows a space for emotions to be } \\
\text { expressed }\end{array}$ & Being able to express suffering \\
\hline & & & Other stakeholders /Facilitator \\
\hline Sharing loss & $\begin{array}{l}\text { Negative experience having shared } \\
\text { information used inappropriately }\end{array}$ & \multicolumn{2}{|c|}{$\begin{array}{l}\text { Understanding of coping behaviours sharing personal information- } \\
\begin{array}{ll}\text { increases } & \text { allowed or gave permission to } \\
\text { open up }\end{array}\end{array}$} \\
\hline Personal difficulties revealed & Increase in valuable/trusted relationships & $\begin{array}{l}\text { Lack of judgement given on any } \\
\text { sharing }\end{array}$ & $\begin{array}{l}\text { Negative experience-not } \\
\text { wanting to share opening }\end{array}$ \\
\hline Hopes, fears, losses & Introduction of hope & \multicolumn{2}{|l|}{ Others feel really heard } \\
\hline How challenges are overcome & Increase in activities & \multicolumn{2}{|l|}{$\begin{array}{l}\text { Knowing someone else is experience } \\
\text { what they are going through- } \\
\text { validation of suffering }\end{array}$} \\
\hline & \multicolumn{3}{|c|}{ Reaffirming a sense of self and self identityDecrease blame on themselves } \\
\hline & Sense of control & \multicolumn{2}{|l|}{ No perceived need to fix problems } \\
\hline & Impact on emotional well being & \multicolumn{2}{|l|}{$\begin{array}{l}\text { Reaffirming a sense of self and self } \\
\text { identity }\end{array}$} \\
\hline & Social well being & \multicolumn{2}{|l|}{ Use of humour } \\
\hline & & \multicolumn{2}{|l|}{$\begin{array}{l}\text { Silence facilitated interaction, } \\
\text { enabled sharing, some were unhappy } \\
\text { with the silence }\end{array}$} \\
\hline
\end{tabular}


Table S9. Synthesis stage 4 the thematic development.

\begin{tabular}{lll}
\hline Theme $\quad$ Subtheme & Code \\
\hline
\end{tabular}

Content of interaction

Openness of sharing personal lived experience

Use of humour

Sharing loss and emotions

Witnessing Hopes, fears, losses

\section{Definition: discussion around the cancer experience}

The group also articulated a broader range of themes, indicating understanding of the cancer experience (3)

Personal stories were salient in as many as $83.6 \%$ of stories $(n=51)$. Participants often talked about their personal hobbies and interests $(57.4 \%, \mathrm{n}=35)$ and their unique attributes $(47.5 \%, \mathrm{n}=29)$. (4)

\section{Definition: Humour}

The stories were not, however, always serious: humour and jokes played a large part in the stories on the list, and were often stressed by the women as being important aspects of survival. (2)

\section{Definition: isolation}

Definition of subtheme: Discussion often focused on participants own fears about living with cancer. Fear for self vs fear for family. Fears about immediate family, fear of cancer coming back. Honesty of exchange. Uncertainty around if the cancer is still their or present.

while all of them expressed emotional concerns related to their cancer disease. (1)

They talked about life, hope, and fear in the context of their personal narratives of the cancer experience: "custody of my grandchild who needed the normal, healthy parent in me," "watching a plant grow under my nurturing care," "living what is today," "fear of suffering, not of dying," and "someone bearing witness to your life." (3)

The personal stories told on the internet had several central and recurrent themes, including breast surgery, sexuality, physical and mental exhaustion, loneliness and fear. (2)

One female participant treated for gynecological cancer said: One year ago they found cancer in my uterus. It only takes a slight amount of pain some-where before I think "oh no" and begin to worry that I might still have cancer. I hope to take something away with me [from the course] to tackle this. It has been a hard journey and it [the cancer] is always in the back of my mind. (1)

Other participants confirmed that with any kind of pain or unfamiliar symptom, uncertainty, and concern followed-the fear that the cancer disease will return. Already during the introduction, it was clear that issues of fear and concern were mentioned as pertinent topics for the participants. (1)

This opening dialogue became the starting point for discussing emotional concerns and worries, being considerate of others and the importance of exploring and clarifying expectations between people who care about one another. (1)

The course can be seen as a storied sequence participants contributed thoughts about how they felt alone with their concerns and fears. One of these fears and concerns being the thought of losing their significant other. One female participant said: I worry, because, how will he manage when I am not there. I think if I die, he will die too. (1) In different ways, they spoke about the fear that cancer provokes and the concerns that they have for each other and their children. In particular, they talked about the fear of the cancer returning or the fear that the cancer had not been fully removed. Several of them commented that: "We were never informed if it [the cancer] can return, nor about the late-effects." (1)

. Only $36.1 \%(n=22)$ of the stories related to cancer or cancer survivors with topics such as treatment (surgery, chemotherapy, radiation or other issues, such as nutrition, exercise, alternative medicine $[40.9 \%, \mathrm{n}=9])$, their diagnosis $(18.2 \%, \mathrm{n}=4)$, their doctors $(22.7 \%, \mathrm{n}$ $=5)$, pain/suffering $(22.7 \%, \mathrm{n}=5)$, and their lingering fears and concerns $(18.2 \%, \mathrm{n}=4)$. Although there were not many cancer-related stories, there were a number of health-related topics, such as narratives on health management practices $(29.5 \%, \mathrm{n}=18)$ 


\begin{abstract}
Outcomes
from

groups

Increased

quality of life
\end{abstract}

Increased

knowledge

Psychologically

healing and needed

shared experience

Shared understanding of coping-shared strategies or their benefits $(14.8 \%, n=9)$. Video sharing via internet (4)

Among the video stories posted on the site, positive stereotypes included mentally strong $(8.25 \%, \mathrm{n}=5)$, brave $(3.3 \%, \mathrm{n}=2)$, able to cope $(6.6 \%, \mathrm{n}=4)$, new insights $(8.2 \%, \mathrm{n}=5)$, and new appreciation for life, friends, and family $(8.2 \%, n=5)$. - contrast to weakness a reliance on character(4)

\section{Definition: Quality of life improves.}

The women stated in interviews and in their postings to each other that participation on the mailing list had greatly improved the quality of their life with breast cancer. (2)

\section{Definition: increased knowledge}

Interviews with participants and observation of the daily storytelling indicated that participation promoted strong awareness of breast cancer and its implications. (2)

Definition: Loneliness is a central consideration coming into the intervention. Need for real exchanges with someone else. How is the isolation created, how is this different from loneliness? - the interactions that follow a cancer diagnosis may influence

Their stories acknowledged that the cancer diagnosis requires the creation of a new map for their lives; that relationships with others are irretrievably altered; that bearing witness to the cancer story, despite its telling and retelling, is a healing gift (3)

After her first visit to the chat room, one woman wrote: 'Time passed so quickly last night and I was on-line 1 hour and 10 minutes. [...] If a laugh is good medicine then the chat was something that can heal, maybe not our breast cancer but our souls." (2)

It is the loneliness I find worst, and that is why it is good the list has started, so we have somebody to share it all with when we need it." (2)

In response, another woman wrote: "I see that $\mathrm{xx}$ writes about loneliness. I recognize my own situation very well in that, and I feel it even more strongly this time $\}$ the absence of people. I miss some of those who would normally get in touch with me. It hurts so badly. Even close friends have disappointed me, they stay away to some extent and I do not know how to tackle this". We found that the community of the mailing list counteracted the experience of social isolation and incorporated the women into a new social world. (2) While another female participant said: My husband is very considerate and tries protecting me, which is a great help. I think he has some gloomy thoughts about my condition, but he doesn't share them with me, and I don't ask. (1)

Social connection and as a well reported item (10)

A subject brought up persistently in postings on the mailing list and in our interviews with the women was the inescapable experience of isolation (2)

Some women described a diagnosis of breast cancer as "being moved to" or "entering" another side of life. They became isolated from their loved ones and from the social world they used to be a part of. The isolation experienced by these women was complex, at times being was experienced as overwhelming. It appeared to be persistent and was a keynote to the stories. "Nobody calls, nobody writes, do they think this is contagious? I am very disappointed\}should I call? I can hardly be bothered now", one woman reported resignedly. Another woman wrote: '[...] (2)

Definition: One outcome for the storytelling is the provision of a shared understanding of illness. The groups provide a natural fit to the need for human interaction. Responses referring to being heard, understanding how to live with the illness. Groups provide a base for knowledge exchange and coping strategies. This knowledge exchange may be unique to the group and may not exist from other sources. - non judgement

Negative case: Benefit of group may depend on the relative condition of the individual

They (storytelling group) were better acquainted with, or had more insight into, not coping compared to the control group (3)

Another motive for turning to the mailing list was to find survivor stories and women to share the experience of breast cancer. Finding personal stories from women who had survived and found ways to live with breast cancer was described as a strong 
encouragement. (2)

The mailing list provided a space in which experiences could be voiced and shared through storytelling. (2)

The women used each other's experiences to learn how to live with illness. One example was the difficult subject of sexuality after breast cancer. In response to a posting on the subject, one woman wrote: 'It is good that you write about this. So far I thought that I was the only one on the list that encountered problems of that kind. (2)

I could write tons of mails on that subject. I love my husband, but I happened to suggest that we got a divorce\}that seemed easier than getting our sex life to work again [...]". Several women encountered both physical and mental difficulties in engaging in the sexual act, and they learned from each other how to confront such problems. Recognition that sex was not what it used to be was central, but they also gave each other practical advice on how to deal with physical discomfort through exercise, various aids and pharmaceutical products. (2)

assistance with a perception of coping and findings other ways to cope (10)

Sixty-seven percent of the respondents (26/39) noticed that they were better able to reach out to others for help and support (10)

The group...described more fully what not coping looked like. (3)

Two women, however, had difficulty determining how to proceed; one felt stuck in a victim role and could not see past that (although she held out hope for the future), and another reported that her skin burned from radiation and that she had feelings of depression. (3)

Although others felt safe in the group, one participant shared some private information despite considering herself "not the type of person to share personal feelings." she reported that this information was later revisited in a joking manner within the group. "i didn't feel $i$ had the freedom to say that i didn't appreciate that ... but it showed me that you have to still be very careful." The participant also expressed conflicting thoughts about the way the storytelling group was run. (3)

Most of the participants said that they initially found it difficult and intimidating to talk about their illness experiences in front of others (1)

Definition: benefit of hope

Introduction of hope Using the internet to find information or support gives women the possibility to act when they had thought that impossible. (2) introduction of hope from hearing from others, (10)

Increase in activities

Reaffirming a sense of self and self identity

Sense of control and empowerment and knowledge

Impact on emotional well being
Definition benefit of empowerment:

The women described how the breast cancer mailing list worked to empower them, by fostering a sense of control that linked them with resources and promoted well-being. "I feel that via the internet I regained power over my body, because I know everything about my diagnosis, my possibilities and my risk," one woman reported. (2)

The women not only gave each other information about breast cancer but also encouraged each other to formulate expectations and questions for their personal consultations with physicians. (2)

\section{Definition: relatedness and emotional wellbeing.}

You turn to the net to find women who have the same age, diagnosis and treatment as yourself\} if they are alive it is good and gives encouragement\} if they are dead you get sad', one woman explained. (2)

Postings on the list sometimes contained remarks that would elicit laughter, bringing relief to both the writer and the reader (2)

Among other things, they emphasized that what they learned from the "All these 
Social well being

Legitimise experiences sharing and being accepted and having unity in experiences considerations" workshop was an especially good way for them to address and alleviate some of the fear and concerns, which were troubling them. As one female patient expressed it: There I was with "The Lump" inside me and then I got rid of it. Her husband added: I really got something out of the rehab-course, because all the nervousness I have had, has been such a burden and it now is much less. (1) Outcome learning about others feelings and experience was positive, feeling supported by the group and better about oneself, being able to share feelings and concerns. (10) Attention to individual patient suffering was provided by exploration of the stories and not the clinical stories of the disease process (Emblen \& Pesut, 2001). As the group worked together to understand their suffering, one woman was "faced with the fact that i might live, then what?" despite many family members dying of the disease. (3)

Definition: benefit on social well-being

Turning to the internet broke down the social isolation created by the experience of breast cancer. (2)

Receiving benefit from sharing with others who have cancer (10) Forty-six percent (18/39) reported improved family relationships and $44 \%$ (17/39) noted better work relationships. Thirty-three percent (13/39) reported better communication with a spouse/ partner. (10)

Definition: engagement of participants with others in the group

The storytelling group believed that they could share their feelings and feel accepted and secure, despite low energy levels. (3)

The medical narrative, chosen initially by both groups in this project as a way for members to tell their stories in an often-rehearsed, socially sanctioned format, cannot fully express the illness experience. The medical narrative, the short-hand technical language universally used by healthcare providers, furnishes an efficient way for patients to communicate to others about cancer. (3)

She talked about her excited anticipation and preparations for the trip; but when the plane landed, she was in Holland. She suffered: she was lost, cold, and unable to communicate with others but she did the best she could on the unanticipated journey. Others entered into her metaphor for suffering, saying, "it's Holland, and i don't like tulips!" "i'm stuck and i can't read the map," and "i'd rather be in italy with my friends!" They told stories about the loss of familiar, beloved things; shared their sense of vulnerability; and expressed resentment at lost companionship. (3)

Shared laughter also establishes a shared social world (2)

Strong bonds formed between the women who shared stories, surfacing through humour and powerful metaphors of kinship and through expressions of recognition and intimacy. $\underline{(2)}$

Passing on stories about support and care was seen not only as reaching out to others but also as a way of dealing with one's own experience and making it meaningful, leading to maintenance of self-esteem. (2)

The participants listened attentively, several nodded in response to the idea that fear could be seen as a little "Shadow-man," as something they understood and made sense to them. One participant said: "Yes, but the fear is there," and another participant added: "Yes, he comes out [the fear] especially before check-up visits [at the hospital]." Earl then suggested that they could try to take control of their fear; for instance, they could decide to talk to their "Shadow-man" 2 days before check-up visit to get him out from behind the door and into the open.... In the above example, a "Shadow-man" can be seen as a metaphor that provides the participants with an alternative tool to openly express and talk about the emotional burdens they experience. (1)

The Lump" is a short story about a boy named Johnny, who lives alone with his father. One day Johnny's best friend Jack calls him a "stupid pig!" Johnny does not know how to react; his feelings are hurt, he is very unhappy and his pain feels like a hard-round-heavy-Lump. Johnny cannot get rid of the Lump; he brings it home and goes to his room. From then on, whenever Johnny is unhappy or hurt, he feels "the Lump" 
growing bigger...Afterward one participant said: "Wow, this gives me goose bumps, it relates so much to me." Another said: "Yes, it was really good" and others joined in, saying: "this was very thought-provoking." (1)

Enhanced interactions, Definition:

activities or

That realization changed her suffering and she "started dancing again. i gave it up for accomplishments three years!" (3)

thankful that she had found a place to openly discuss her fears about her cancer diagnosis; she was not allowed to do so at home because her husband strictly believed in positive thinking (3)

She also was instructed to avoid gatekeeping that could shut off stories as they began to surface. she countered this by allowing members to each "have their night" if they were severely stressed, emphasizing that the same courtesy would be extended to others as needed (3)

One person monopolizes the group ... whether that person should have been controlled or whether it was good because the person knew they'd be helped. I still haven't quite figured that out because I saw the person change considerably from when they first started the group (3)

Also indicated was a beginning acceptance by the woman who provided the outlier statements that, when the "monopolizer" worked to heal herself in the context of the group, she "contributed to the healing of the whole" (3)

We often found that humour was used in mailing list conversations to create distance from an event or situation. Seeking advice on "Shampoo for bald-headed people" or joking about the forgetfulness of "chemo brains" and about ill-fitting breast prostheses are examples of jokes shared on the mailing list with sympathetic understanding (2)

Allows a space for Mechanisms emotions to be expressed
Understanding of coping behaviours increases

Lack of judgement give on any sharing

Others feel really heard

Knowing someone else is experience what they are going throughvalidation of suffering
"What you experience on the list is the opportunity to give, to give love to each other", one woman explained in an interview. The social nature of the breast cancer mailing list was expressed as genuine concern for others. (2)

As to motivation, $80 \%$ of the children/adolescents were animated and $60 \%$ showed curiosity. The animation was evidenced through smiles and excitement when retelling the story, in the manipulation of the materials and the interaction with the people present. (5) Of the 20 children/adolescents participating in the study, nine (45\%) changed to a happier emotion, 10 (50\%) participants remained in the same category of emotion, all of whom were already in a positive emotional state or very cheerful) and only one changed to a sadder emotion (5\%) after the Story Box. The participant who remained in a sad emotional state did not interact with other people and was not motivated during the practice. However, the participant who decreased his score, despite interacting with other people and being motivated, changed his emotional state from very cheerful to cheerful (from 4 to 3 ). (5)

Analyzing the results before and after storytelling, it was possible to see that children and adolescents significantly modified their emotional state, with $p$ value equal to 0.0111 , as can be seen in Table 1 (5)

that the use of art as a therapeutic resource assists in the development of free expression and enables the understanding and interpretation of children's experiences and adolescents with cancer, improving their quality of life. (5)

Attention to individual patient suffering was provided by exploration of the stories and not the clinical stories of the disease process (Emblen \& Pesut, 2001). As the group worked together to understand their suffering, one woman was "faced with the fact that i might live, then what?" despite many family members dying of the disease. That realization changed her suffering and she "started dancing again. i gave it up for three years!" (3) She avoided probing discussions on coping strategies but worked to get in touch with participants through an interpersonal bridge created, in part, by her own self-disclosure (3)

Participants telling and retelling their stories to one another as they worked to make meaning from the cancer experience (3)

The medical narrative, chosen initially by both groups in this project as a way for members to tell their stories in an often-rehearsed, socially sanctioned format, cannot fully express 
the illness experience. The medical narrative, the short-hand technical language universally used by healthcare providers, furnishes an efficient way for patients to communicate to others about cancer. (3)

Some expected that it was going to be like "going to camp" and looked forward to meeting others that were in a similar situation with similar circumstances (1).

Overwhelmingly, the most favorable aspect of the group was the sharing and the stories as noted by over half the participants ( 25 of 39 ). A sample quote was "Each group member listen (ed) to me and the one thing I truly needed was to be able to talk \& know some one cared. (10)

Frequent retelling may have occurred because stories allow people to forget and reinvent certain aspects of their pasts, making them more acceptable in current circumstances (3)

Retelling a story to reframe its content $=$ Decrease blame on themselves Shared social experience The stories often need to be re-explored for meaning in light of what participants now know. Revised versions then are used to validate identities and suffering, for both the participant and the group. Such validation was appreciated by one woman who said, "The group helped me see that the things that were happening weren't because of a failure on my part or something i had done wrong, or not done." (3)

Shared laughter also establishes a shared social world, and on several occasions women on the mailing list said that they enjoyed talking to each other "[...] because we can laugh at the same things". (2)

The nurse facilitator was able to avoid judging, analyzing, and extracting data from the No perceived need to fix stories and seemed to accept them as whole and true to the teller (3) problems (similar to lackgroup members discussed bearing witness to each other's stories with the guidance of the of judgement?) nurse facilitator, recognizing that it was not about fixing the issue or even having something to say, but just being with people (3)

Reaffirming a sense of self and self identity

Those strategies were aimed at producing "virtually shared experiences" (Errante, p. 24) that allowed group members to vicariously enter the storytellers' realities and work toward shared meaning (Watson, 2003). (3)

Use of humour

group members discussed bearing witness to each other's stories with the guidance of the nurse facilitator, recognizing that it was not about fixing the issue or even having something to say, but just being with people... acknowledging who they were, and Trust and Unity in reminding them that their disease did not define or tarnish them. (3) sharing and being with Many stressed that the absence of physical contact on the internet made it easier to start people discussions on difficult and painful subjects, whereas the intimacy and trust formed on-line created the basis for discussions when the women met face-to-face. It was not the anonymity of the internet but rather the lack of physical contact at the time of writing that proved helpful to the women. (2)

One male participant said: There is a difference between how we think others are doing and how they are actually doing. Earl responded: Yes, sometimes we think we know how

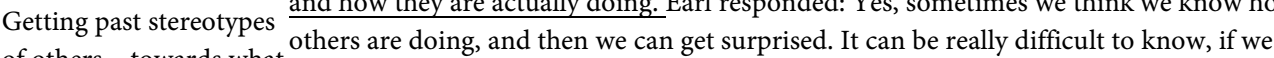
of others - towards what their lives are like (content of interaction) don't talk about it. (1)

On the other hand, there were some health-related words, such as "healthy," "tired," or "sporty." About half of the participants listed health-related words in their description of themselves; 30.8\% ( $\mathrm{n}=4)$ listed one word and 15.4\% $(\mathrm{n}=2)$ listed two.(4)

Silence facilitated interaction, enabled sharing, some were Silences in the group were documented as natural and comfortable. group members appeared to reflect on or con template stories just disclosed. (3) unhappy with the silence

Factors which influence benefit
The facilitator suspended her usual role as an authority figure to become vulnerable and acknowledge her own humanity..."it was like my own personal therapy session, only Space where openness is better because you shared your experience, too." (3) possible-prevented in other interactions

. First of all, we found that participants avoided cancer-related topics in general. Only

$19.7 \%$ of video postings $(n=12)$ had a direct reference to cancer. Type of communication - video posting prevented interaciton (4)

Showed the activities performed for team members or other people and talked about their

Having others to talk to daily lives. Interaction with the couple of undergraduates occurred for $90 \%$ of the children/adolescents and the interaction with other children/adolescents, for only $30 \%$ of 
the participants. (5)

Among the participants who improved their scores, $55 \%$ interacted with the couple of undergraduates and/or with other children and adolescents and were motivated (showing excitement and curiosity). (5)

For example, many listed words, such as "talkative"/“loud" (as opposed to "quiet") or "fun to hang out with"/"fun to be around" (as opposed to "isolated"). Moreover, one of the most frequently listed identity words among all the words describing self was "smart" (as opposed to "dumb"). In total, $77 \%$ of participants listed at least one of these antonyms to describe themselves. (4)

Domination of one member of the group

Being able to express suffering or engage

Other stakeholders /Facilitator sharing personal informationallowed or gave permission to open up

Negative experiencenot wanting to share opening

Being able to confront fear
Women with a new diagnosis entered the list to seek the experience and advice of women who had already lived through surgery and various treatments, whereas women who had lived some years with breast cancer gratefully took the opportunity of telling their stories. $\underline{(2)}$ $100 \%$ of the children/adolescents maintained their attention in history, a fact observed through the attentive gaze in the staging and through the changes in the facial expression, coherent with the unfolding of the story (5)

A significant positive relationship between negative stereotypes expressed in the "Who Am I" test and depression was observed (for frequency, $r=0.63, p<0.01$; for percentage, $r=$ $0.51, p<0.05)(4)$

In terms of acceptance of a cancer survivor identity, just more than $80 \%$ of stories indicated their acceptance of a cancer survivor identity $(n=18) .(4)$

Note: 1 = La Cour et al. (2016); 2 = Høybye et al. (2005); 3 = Evans et al. (2008), 4 = Song et al. (2012), 5 = Garcia-Schinzari et al. (2014); 6 = Ando et al, (2018); 7 = Crogan et al. (2008); 8 = Falzon et al. (2015); 9 = Heiney et al. (2012); 10 = Heiney et al. (2013); 11 = Heiney et al. (2015).

Table S10. Synthesis stage 5 the second phase of the thematic development.

Theme Subtheme $\begin{aligned} & \text { Code } \\ & \text { Definition of subtheme: Discussion often focused on participants own fears about living } \\ & \text { with cancer. Fear for self vs fear for family. Fears about immediate family, fear of cancer } \\ & \text { coming back. Honesty of exchange. Uncertainty around if the cancer is still their or } \\ & \text { present. } \\ & \text { while all of them expressed emotional concerns related to their cancer disease. (1) } \\ & \text { They talked about life, hope, and fear in the context of their personal narratives of the } \\ & \text { Content of Witnessing Hopes, fears, cancer experience: "custody of my grandchild who needed the normal, healthy parent in } \\ & \text { me," "watching a plant grow under my nurturing care," "living what is today," "fear of } \\ & \text { suffering, not of dying," and "someone bearing witness to your life." (3) } \\ & \text { The personal stories told on the internet had several central and recurrent themes, } \\ & \text { including breast surgery, sexuality, physical and mental exhaustion, loneliness and fear. (2) } \\ & \text { One female participant treated for gynecological cancer said: One year ago they found } \\ & \text { cancer in my uterus. It only takes a slight amount of pain some-where before I think "oh } \\ & \text { no" and begin to worry that I might still have cancer. I hope to take something away with } \\ & \text { me [from the course] to tackle this. It has been a hard journey and it [the cancer] is always }\end{aligned}$


in the back of my mind. (1)

Other participants confirmed that with any kind of pain or unfamiliar symptom, uncertainty, and concern followed-the fear that the cancer disease will return. Already during the introduction, it was clear that issues of fear and concern were mentioned as pertinent topics for the participants. (1)

This opening dialogue became the starting point for discussing emotional concerns and worries, being considerate of others and the importance of exploring and clarifying expectations between people who care about one another. (1)

The course can be seen as a storied sequence participants contributed thoughts about how they felt alone with their concerns and fears. One of these fears and concerns being the thought of losing their significant other. One female participant said: I worry, because, how will he manage when I am not there. I think if I die, he will die too. (1) In different ways, they spoke about the fear that cancer provokes and the concerns that they have for each other and their children. In particular, they talked about the fear of the cancer returning or the fear that the cancer had not been fully removed. Several of them commented that: "We were never informed if it [the cancer] can return, nor about the late-effects." (1)

. Only $36.1 \%(n=22)$ of the stories related to cancer or cancer survivors with topics such as treatment (surgery, chemotherapy, radiation or other issues, such as nutrition, exercise, alternative medicine $[40.9 \%, \mathrm{n}=9]$ ]), their diagnosis $(18.2 \%, \mathrm{n}=4)$, their doctors $(22.7 \%, \mathrm{n}$ $=5)$, pain/suffering $(22.7 \%, n=5)$, and their lingering fears and concerns $(18.2 \%, n=4)$. Although there were not many cancer-related stories, there were a number of health-related topics, such as narratives on health management practices $(29.5 \%, \mathrm{n}=18)$ or their benefits $(14.8 \%, n=9)$. Video sharing via internet (4)

Among the video stories posted on the site, positive stereotypes included mentally strong $(8.25 \%, \mathrm{n}=5)$, brave $(3.3 \%, \mathrm{n}=2)$, able to cope $(6.6 \%, \mathrm{n}=4)$, new insights $(8.2 \%, \mathrm{n}=5)$, and new appreciation for life, friends, and family $(8.2 \%, n=5)$. - contrast to weakness a reliance on character(4)

Definition: Loneliness is a central consideration coming into the intervention. Need for real exchanges with someone else. How is the isolation created, how is this different from loneliness? - the interactions that follow a cancer diagnosis may influence

Their stories acknowledged that the cancer diagnosis requires the creation of a new map for their lives; that relationships with others are irretrievably altered; that bearing witness to the cancer story, despite its telling and retelling, is a healing gift (3)

After her first visit to the chat room, one woman wrote: "Time passed so quickly last night and I was on-line 1 hour and 10 minutes. [...] If a laugh is good medicine then the chat was something that can heal, maybe not our breast cancer but our souls." (2)

It is the loneliness I find worst, and that is why it is good the list has started, so we have somebody to share it all with when we need it. (2)

In response, another woman wrote: "I see that $\mathrm{xx}$ writes about loneliness. I recognize my own situation very well in that, and I feel it even more strongly this time\} the absence of

Outcomes from groups
Psychologically healing and needed shared experience people. I miss some of those who would normally get in touch with me. It hurts so badly. Even close friends have disappointed me, they stay away to some extent and I do not know how to tackle this". We found that the community of the mailing list counteracted the experience of social isolation and incorporated the women into a new social world. (2) While another female participant said: My husband is very considerate and tries protecting me, which is a great help. I think he has some gloomy thoughts about my condition, but he doesn't share them with me, and I don't ask. (1)

Social connection and as a well reported item (10)

A subject brought up persistently in postings on the mailing list and in our interviews with the women was the inescapable experience of isolation (2)

Some women described a diagnosis of breast cancer as "being moved to" or "entering" another side of life. They became isolated from their loved ones and from the social world they used to be a part of. The isolation experienced by these women was complex, at times being was experienced as overwhelming. It appeared to be persistent and was a keynote to the stories. "Nobody calls, nobody writes, do they think this is contagious? I am very disappointed\} should I call? I can hardly be bothered now", one woman reported resignedly. Another woman wrote: "[...]" (2) 
The group also articulated a broader range of themes, indicating understanding of the cancer experience (3)

Personal stories were salient in as many as $83.6 \%$ of stories $(n=51)$. Participants often talked about their personal hobbies and interests $(57.4 \%, \mathrm{n}=35)$ and their unique attributes $(47.5 \%, \mathrm{n}=29)$. (4)

Small non significant improvements in spiritual well being and hope-identifying that the scale may not be capturing change. (6)

Index of Clinical Stress (Abell, 1991) show significant interaction. Story group felt less stressed over time $(\mathrm{P}<0.05, \mathrm{~F}$ 12.2) where as control group felt more stressed. (7) No significant impact on depression, physical self efficacy or pain (7) fatalism and fear significantly decreased in the storytelling group. (9) post treatment depression $(\mathrm{Z}=-1.49, \mathrm{p}=0.14$; $)$ and fatigue $(\mathrm{Z}=-0.13, \mathrm{p}=0.90)$ slightly higher for control group vs storytelling group (10)

I liked sharing with other women with breast cancer (mean 3.81SD 0.39 out of a possible 4 as agreement with statement) (11)

The group helped me feel better about myself (mean 3.79SD0.41 out of a possible 4 as agreement with statement) (11)

Definition: One outcome for the storytelling is the provision of a shared understanding of illness. The groups provide a natural fit to the need for human interaction. Responses referring to being heard, understanding how to live with the illness. Groups provide a base for knowledge exchange and coping strategies. This knowledge exchange may be unique to the group and may not exist from other sources. —non judgement

Negative case: Benefit of group may depend on the relative condition of the individual

They (storytelling group) were better acquainted with, or had more insight into, not coping compared to the control group (3)

Another motive for turning to the mailing list was to find survivor stories and women to share the experience of breast cancer. Finding personal stories from women who had survived and found ways to live with breast cancer was described as a strong encouragement. (2)

The mailing list provided a space in which experiences could be voiced and shared through storytelling. (2)

The women used each other's experiences to learn how to live with illness. One example was the difficult subject of sexuality after breast cancer. In response to a posting on the subject, one woman wrote: "It is good that you write about this. So far I thought that I was

Shared understanding of coping-shared strategies the only one on the list that encountered problems of that kind. (2)

I could write tons of mails on that subject. I love my husband, but I happened to suggest that we got a divorce\} that seemed easier than getting our sex life to work again [...]". Several women encountered both physical and mental difficulties in engaging in the sexual act, and they learned from each other how to confront such problems. Recognition that sex was not what it used to be was central, but they also gave each other practical advice on how to deal with physical discomfort through exercise, various aids and pharmaceutical products. (2)

assistance with a perception of coping and findings other ways to cope (10) Sixty-seven percent of the respondents (26/39) noticed that they were better able to reach out to others for help and support (10)

The group...described more fully what not coping looked like. (3)

Two women, however, had difficulty determining how to proceed; one felt stuck in a victim role and could not see past that (although she held out hope for the future), and another reported that her skin burned from radiation and that she had feelings of depression. (3)

Although others felt safe in the group, one participant shared some private information despite considering herself "not the type of person to share personal feelings." she reported that this information was later revisited in a joking manner within the group. "I didn't feel $i$ had the freedom to say that i didn't appreciate that ... but it showed me that you have to still be very careful." The participant also expressed conflicting thoughts about the way the 
Impact on emotional well being

Social well being

Legitimise experiences; sharing and being accepted and having unity in experiences storytelling group was run. (3)

Most of the participants said that they initially found it difficult and intimidating to talk about their illness experiences in front of others (1)

The group helped me cope with having cancer (mean 3.74SD0.44 out of a possible 4 as agreement with statement) (11)

I learned other ways to deal with problems (mean 3.56 SD 0.55)

Definition: relatedness and emotional wellbeing.

You turn to the net to find women who have the same age, diagnosis and treatment as yourself if they are alive it is good and gives encouragement if they are dead you get sad', one woman explained. (2)

Postings on the list sometimes contained remarks that would elicit laughter, bringing relief to both the writer and the reader (2)

Among other things, they emphasized that what they learned from the "All these considerations" workshop was an especially good way for them to address and alleviate some of the fear and concerns, which were troubling them. As one female patient expressed it: There I was with "The Lump" inside me and then I got rid of it. Her husband added: I really got something out of the rehab-course, because all the nervousness I have had, has been such a burden and it now is much less. (1)

Outcome learning about others feelings and experience was positive, feeling supported by the group and better about oneself, being able to share feelings and concerns. (10) Attention to individual patient suffering was provided by exploration of the stories and not the clinical stories of the disease process (Emblen \& Pesut, 2001). As the group worked together to understand their suffering, one woman was "faced with the fact that i might live, then what?" despite many family members dying of the disease. (3)

I was able to express my feelings (mean 3.72SD 0.45 out of a possible agreement of 4 with the statement) (11)

I was able to express my concern in the group (mean 3.72SD0.45 out of a possible agreement of 4 with the statement) (11)

Definition: benefit on social or well-being, with a direct benefit on isolation and from others. Groups also reported increase in family and work relationships. Significant increases of social connections increased and individual reported agreeing that they were supported by the group.

Turning to the internet broke down the social isolation created by the experience of breast cancer. (2)

Receiving benefit from sharing with others who have cancer (10)

Forty-six percent (18/39) reported improved family relationships and 44\% (17/39) noted better work relationships. Thirty-three percent (13/39) reported better communication with a spouse/partner. (10)

Non significant improvement in life satisfaction $(6,7)$

Social connection measured with the SWB subscale improved significantly in the intervention group (9)

I felt supported by the group members (mean 3.87SD0.34 out of a possible agreement of 4 with the statement) (11)

Definition: engagement of participants with others in the group/ The group was a space where individual could share their own feelings

The storytelling group believed that they could share their feelings and feel accepted and secure, despite low energy levels. (3)

the medical narrative, chosen initially by both groups in this project as a way for members to tell their stories in an often-rehearsed, socially sanctioned format, cannot fully express the illness experience. The medical narrative, the short-hand technical language universally used by healthcare providers, furnishes an efficient way for patients to communicate to others about cancer. (3) She talked about her excited anticipation and preparations for the trip; but when the plane 
landed, she was in Holland. She suffered: she was lost, cold, and unable to communicate with others but she did the best she could on the unanticipated journey. Others entered into her metaphor for suffering, saying, "it's Holland, and i don't like tulips!" “i'm stuck and i can't read the map," and "i'd rather be in italy with my friends!" They told stories about the loss of familiar, beloved things; shared their sense of vulnerability; and expressed resentment at lost companionship. (3)

Shared laughter also establishes a shared social world (2)

Strong bonds formed between the women who shared stories, surfacing through humour and powerful metaphors of kinship and through expressions of recognition and intimacy. (2)

Passing on stories about support and care was seen not only as reaching out to others but also as a way of dealing with one's own experience and making it meaningful, leading to maintenance of self-esteem. (2)

The participants listened attentively, several nodded in response to the idea that fear could be seen as a little "Shadow-man," as something they understood and made sense to them. One participant said: "Yes, but the fear is there," and another participant added: "Yes, he comes out [the fear] especially before check-up visits [at the hospital]." Earl then suggested that they could try to take control of their fear; for instance, they could decide to talk to their "Shadow-man" 2 days before check-up visit to get him out from behind the door and into the open.... In the above example, a "Shadow-man" can be seen as a metaphor that provides the participants with an alternative tool to openly express and talk about the emotional burdens they experience. (1)

The Lump" is a short story about a boy named Johnny, who lives alone with his father. One day Johnny's best friend Jack calls him a "stupid pig!" Johnny does not know how to react; his feelings are hurt, he is very unhappy and his pain feels like a hard-round-heavy_Lump. Johnny cannot get rid of the Lump; he brings it home and goes to his room. From then on, whenever Johnny is unhappy or hurt, he feels "the Lump" growing bigger ... Afterward one participant said: "Wow, this gives me goose bumps, it relates so much to me." Another said: "Yes, it was really good" and others joined in, saying: "this was very thought-provoking." (1)

Source trust (belief and trust in the source of this message) was higher in Story group compared to comparison group $(\mathrm{T}=-10.61, \mathrm{p}<0.001)(8)$

Source trust was positively related to positive exercise related behaviours (8)

I liked sharing with other women with breast cancer (mean 3.84 SD 0.37 out of a possible agreement of 4 with statement) (11)

I could share thoughts in the group that I could not share with most people (mean $3.63 \mathrm{SD}$ 0.49 out of a possible agreement of 4 with statement) (11)

Factors or

Mechanisms Allows a space for that emotions to be influenced expressed and the expe- validation of suffering rience
Definition: content of discussion was important being able to share opening about feelings was important.

thankful that she had found a place to openly discuss her fears about her cancer diagnosis; she was not allowed to do so at home because her husband strictly believed in positive thinking (3)

she also was instructed to avoid gatekeeping that could shut off stories as they began to surface. she countered this by allowing members to each "have their night" if they were severely stressed, emphasizing that the same courtesy would be extended to others as needed (3) one person monopolizes the group ... whether that person should have been controlled or whether it was good because the person knew they'd be helped. I still haven't quite figured that out because I saw the person change considerably from when they first started the group (3)

Also indicated was a beginning acceptance by the woman who provided the outlier statements that, when the "monopolizer" worked to heal herself in the context of the group, she "contributed to the healing of the whole" (3)

We often found that humour was used in mailing list conversations to create distance from an event or situation. Seeking advice on "Shampoo for bald-headed people" or joking 
about the forgetfulness of "chemo brains" and about ill-fitting breast prostheses are examples of jokes shared on the mailing list with sympathetic understanding (2) "What you experience on the list is the opportunity to give, to give love to each other", one woman explained in an interview. The social nature of the breast cancer mailing list was expressed as genuine concern for others. (2)

As to motivation, $80 \%$ of the children/adolescents were animated and $60 \%$ showed curiosity. The animation was evidenced through smiles and excitement when retelling the story, in the manipulation of the materials and the interaction with the people present. (5) Of the 20 children/adolescents participating in the study, nine (45\%) changed to a happier emotion, 10 (50\%) participants remained in the same category of emotion, all of whom were already in a positive emotional state or very cheerful) and only one changed to a sadder emotion (5\%) after the Story Box. The participant who remained in a sad emotional state did not interact with other people and was not motivated during the practice. However, the participant who decreased his score, despite interacting with other people and being motivated, changed his emotional state from very cheerful to cheerful (from 4 to 3). (5)

Analyzing the results before and after storytelling, it was possible to see that children and adolescents significantly modified their emotional state, with $\mathrm{p}$ value equal to 0.0111 , as can be seen in Table 1 (5)

that the use of art as a therapeutic resource assists in the development of free expression and enables the understanding and interpretation of children's experiences and adolescents with cancer, improving their quality of life. (5)

The nurse facilitator was able to avoid judging, analyzing, and extracting data from the stories and seemed to accept them as whole and true to the teller (3)

group members discussed bearing witness to each other's stories with the guidance of the nurse facilitator, recognizing that it was not about fixing the issue or even having something to say, but just being with people (3) group members discussed bearing witness to each other's stories with the guidance of the nurse facilitator, recognizing that it was not about fixing the issue or even having something to say, but just being with people ... acknowledging who they were, and reminding them that their disease did not define or tarnish them. (3) Many stressed that the absence of physical contact on the internet made it easier to start discussions on difficult and painful subjects, whereas the intimacy and trust formed on-line created the basis for discussions when the women met face-to-face. It was not the anonymity of the internet but rather the lack of physical contact at the time of writing that proved helpful to the women. (2)

silences in the group were documented as natural and comfortable. group members appeared to reflect on or con template stories just disclosed. (3)

the facilitator suspended her usual role as an authority figure to become vulnerable and acknowledge her own humanity ... "it was like my own personal therapy session, only better because you shared your experience, too." (3)

. First of all, we found that participants avoided cancer-related topics in general. Only $19.7 \%$ of video postings $(n=12)$ had a direct reference to cancer. Type of communication - video posting prevented interaction (4)

For example, many listed words, such as "talkative"/"loud" (as opposed to "quiet") or "fun to hang out with"/"fun to be around" (as opposed to "isolated"). Moreover, one of the most frequently listed identity words among all the words describing self was "smart" (as opposed to "dumb"). In total, $77 \%$ of participants listed at least one of these antonyms to describe themselves. (4)

participants telling and retelling their stories to one another as they worked to make meaning from the cancer experience (3)

the medical narrative, chosen initially by both groups in this project as a way for members to tell their stories in an often-rehearsed, socially sanctioned format, cannot fully express the illness experience. The medical narrative, the short-hand technical language universally used by healthcare providers, furnishes an efficient way for patients to communicate to others about cancer. (3)

Some expected that it was going to be like "going to camp" and looked forward to meeting 
others that were in a similar situation with similar circumstances (1)

. Overwhelmingly, the most favorable aspect of the group was the sharing and the stories as noted by over half the participants ( 25 of 39). A sample quote was "Each group member listen (ed) to me and the one thing I truly needed was to be able to talk \& know some one cared. (10)

Those strategies were aimed at producing "virtually shared experiences" (Errante, p. 24) that allowed group members to vicariously enter the storytellers' realities and work toward shared meaning (Watson, 2003). (3)

It was good to learn from other patients about their feelings (mean 3.97SD 0.16 out of a possible score of 4.0 for agreement with statement) (11)

Definition: a need to re-explore meaning

Frequent retelling may have occurred because stories allow people to forget and reinvent certain aspects of their pasts, making them more acceptable in current circumstances (3)

Retelling a story to The stories often need to be re-explored for meaning in light of what participants now reframe its content $=$ know. Revised versions then are used to validate identities and suffering, for both the Decrease blame on participant and the group. Such validation was appreciated by one woman who said, "The themselves group helped me see that the things that were happening weren't because of a failure on Shared social experience my part or something i had done wrong, or not done." (3)

Shared laughter also establishes a shared social world, and on several occasions women on the mailing list said that they enjoyed talking to each other "[...] because we can laugh at the same things". (2)

Note: 1 = La Cour et al. (2016); 2 = Høybye et al. (2005); 3 = Evans et al. (2008); 4 = Song et al. (2012); 5 = Garcia-Schinzari et al. (2014); 6 = Ando et al., (2018); 7 = Crogan et al. (2008); 8 = Falzon et al. (2015); 9 = Heiney et al. (2012); 10 = Heiney et al. (2015); 11 = Heiney et al. (2013). 